\title{
Cyclic behaviour of double-tube buckling-restrained braces for boiler steel plant structures
}

DOI:

10.1016/j.jcsr.2018.08.022

Document Version

Accepted author manuscript

Link to publication record in Manchester Research Explorer

\section{Citation for published version (APA):}

Xu, F., Chen, J., Shu, K., \& Su, M. (2018). Cyclic behaviour of double-tube buckling-restrained braces for boiler steel plant structures. Journal of Constructional Steel Research, 150, 556-569.

https://doi.org/10.1016/j.jcsr.2018.08.022

\section{Published in:}

Journal of Constructional Steel Research

\section{Citing this paper}

Please note that where the full-text provided on Manchester Research Explorer is the Author Accepted Manuscript or Proof version this may differ from the final Published version. If citing, it is advised that you check and use the publisher's definitive version.

\section{General rights}

Copyright and moral rights for the publications made accessible in the Research Explorer are retained by the authors and/or other copyright owners and it is a condition of accessing publications that users recognise and abide by the legal requirements associated with these rights.

\section{Takedown policy}

If you believe that this document breaches copyright please refer to the University of Manchester's Takedown Procedures [http://man.ac.uk/04Y6Bo] or contact uml.scholarlycommunications@manchester.ac.uk providing relevant details, so we can investigate your claim.

\section{OPEN ACCESS}


Xu, F., Chen, J, Shu K., Su, M.N., (2018), "Cyclic behaviour of double-tube buckling-restrained braces for boiler steel plant structures", Journal of Constructional Steel Research, 150: 556-569

\section{Cyclic behaviour of double-tube buckling-restrained braces for boiler}

\section{steel plant structures}

Fei Xu ${ }^{2}, \mathrm{Ju}_{\mathrm{Chen}}{ }^{*}, \mathrm{Ke} \mathrm{Shu}^{1}, \mathrm{Mei}-\mathrm{ni} \mathrm{Su}^{3}$

1. Institute of Structural Engineering, Zhejiang University, Hangzhou, Zhejiang, China

2. Department of Civil and Environmental Engineering, The Hong Kong Polytechnic University, Hong Kong, China

3. School of Mechanical, Aerospace and Civil Engineering, The University of Manchester, Manchester, UK

Abstract: An inner-stiffened double-tube buckling-restrained brace (BRB) is proposed for boiler steel plants in the low-to-medium seismicity regions. The test specimen is of $15.0 \mathrm{~m}$ length, consisting of a $15.0 \mathrm{~m}$ inner tube with inner stiffeners at both ends and a $12.2 \mathrm{~m}$ outer tube for lateral deformation restraint. The full-scale test was conducted to reproduce the cyclic behaviour of the proposed double-tube steel BRB in the plant structures at a practical manufacturing level. The structural performance of the proposed BRB under extremely low cycle fatigue (ELCF), including the strength, deformation capacity, hysteretic response and the failure mode, was investigated. The finite element (FE) model incorporating a material fracture model was established and verified, which could predict the fracture initiation and propagation accurately. The parametric study was carried out to further assess the influence of the stiffener arrangement, material property, gap size and controlling metric of the imperfection on the cyclic behaviour of the proposed BRB. The experimental and numerical investigations demonstrated that the proposed braces could achieve a stable and saturated hysteretic curve. The failure mode was the stress concentration induced fracture which initiated at the inner surface of the inner tube at the stiffener tips. On the basis of the parametric study, the optimized BRB could achieve a high equivalent ratio of critical viscous damping at the loading amplitude of $1 / 75 \mathrm{~L}$.

Keyword: Stiffened double-tube, Buckling-restrained, Extremely-low cycle fatigue, Hysteretic response, Fracture

*Corresponding author: cecj@zju.edu.cn 
31 Steel concentrically braced frames are prevailing in buildings and infrastructures serving as the lateral-action resisting system. The brace acts as an energy-dissipation member though yielding at the tensile loading and buckling at the compressive loading while providing the lateral action resistant. However, the buckling of bracing members is inevitable during the major earthquake. It can cause the deteriorations of the strength and stiffness especially during the compressive hysteresis excursions, compromise the energy-dissipation ability and ultimately lead to the premature fracture. The un-symmetrical performance under tensile and compressive loadings and the unexpected failure of bracing members can cause the unfavourable load re-distribution within the members of the frames, the storey-drift concentration and the increased risk of structure collapse. Therefore, the buckling restrained brace (BRB) based on the motivations of restraining the brace buckling to achieve a symmetrical performance under both tensile and compressive loading conditions, was proposed and investigated in 1970s [1-3].

During past few decades, the buckling-restrained braced frames have been widely adopted in the high-rise buildings and infrastructures in the high seismicity regions, owing to the satisfactory seismic performance. Various types of BRBs have been developed, which can be catalogued as the mortar restrained-system [4-7] and the plain steel restrained-system [813]. Compared with the former mortar-restrained BRBs, the plain steel ones are friendly for the post-earthquake inspection and the re-use of the buckling-restraining elements [13]. The different types of the core members for the plain steel BRBs, i.e. tubular [8-12] and nontubular forms [13], have been proposed and investigated in the previous research. The hollow tubular-core BRBs, consisting of double or tribble overlapped tubes, present the advantages in the fabrication and the capacity to self-weight ratio compared with the counterpart one, especially when adopted in the large-scale structures with the dimension larger than $10 \mathrm{~m}$, 
such as the steel frames in the thermal power plants.

The structure of the boiler workshop in the thermal power plants are of significance and the safety of the steel structures should be ensured to enable the non-interrupting or promptly resilience of the electricity supply after strong earthquakes. However, due to the special requirements of the thermal power generation reacting furnace and the corresponding arrangements of the pipelines and the affiliated equipment, the plant structures generally exhibit horizontal and vertical irregularities with unevenly-distributed gravity loads. Furthermore, the large dimension members and spans are commonly adopted in the plant structures, considering the practical issues such as minimizing steel usage, reducing the transportation times, and optimizing the construction plan. Therefore, the lengths of bracing members generally range from $10 \mathrm{~m}$ to $25 \mathrm{~m}$, even longer in a large-scale thermal power plant. Under these circumstances, the conventional bracing members may fail to meet all the requirements while having a reasonable and economical member dimension for the fabrication, transportation and installation. In addition, the limited out-of-plane space in the boiler plants can also hinder their applications in the boiler plant structures. Previous research [14-15] showed the significantly improved seismic performance of the thermal plant structures after incorporating BRBs. This superior performance can be secured providing that the large-scale BRBs can behave satisfactorily. Due to the large dimension, the increasing difficulties of the fabrication and contribution could be the predominant issues to affect the seismic performance of BRBs. However, scarce research was performance on the large-scale BRB (longer than $12.0 \mathrm{~m}$ ).

A stiffened double-tube buckling-restrained brace (SDT-BRB) is proposed for the application in boiler steel plants in this study. A full-scale test on a 15-m SDT-BRB specimen was conducted to investigate the influence of the large-scale size and the corresponding practical issues on the performance of the proposed BRB. Finite element (FE) analyses were employed to further assess the effects of the stiffener arrangement, material, gap size and 
81 imperfection on the hysteretic response and ductility capacity of the proposed BRB. Finally, the recommendations to achieve satisfactory hysteretic performance were given for the practical design.

\section{2. Experimental investigation}

\subsection{Test specimen}

A 15-m full-scale stiffened double-tube BRB was fabricated by two cold-formed circular hollow section (CHS) tubes. The inner and outer tubes were manufactured by the cold-form process and welded by one straight seam weld. The schematic view of the test specimen is shown in Fig. 1(a). The diameters and thicknesses for inner $\left(D_{\mathrm{i}} \times T_{\mathrm{i}}\right)$ and outer tubes $\left(D_{\mathrm{o}} \times T_{\mathrm{o}}\right)$ were $480 \mathrm{~mm} \times 14 \mathrm{~mm}$ and $550 \mathrm{~mm} \times 25 \mathrm{~mm}$, respectively. The total lengths of inner and outer tubes were $15.0 \mathrm{~m}$ and $12.2 \mathrm{~m}$, respectively. Eight longitudinal inner stiffeners with the thickness of $25 \mathrm{~mm}$ were welded at both ends in every 22.5 degree, as shown in Fig. 1(a). In addition, six $45^{\circ}$-circular-arc plates with thickness of $14 \mathrm{~mm}$ were welded to the inner stiffeners within the region of $1900 \mathrm{~mm}$, to ensure the lateral stability of each stiffener. The inner and ring stiffeners were designed to prevent the local buckling of the inner tube beyond the outer tube while being in the elastic stage during the test. The gap between the ring stiffeners and the inner tube as well as the gap between the inner and outer tubes were both $10 \mathrm{~mm}$. Four M20 bolts were used to align the inner and outer tubes at the mid-length at each $90^{\circ}$, as a construction measurement. Eight 3-mm-thick rubber strips with the width of 1/16 circumference of the inner tube were mounted on the external surface of the inner tube-wall within the contact region of these two tubes. The rubber strips could mitigate the hard contact between two tubes.

The detailed information and assembling of each component are described in Figs. 1(a) and (b). The test specimens were made of Q235 steel (nominal yield strength of $235 \mathrm{MPa}$ ) The mechanical properties of the yield strength, the ultimate strength and the Young's 
106 modulus derived from tensile coupon tests from the reference tube sample were list in Table 1071.

109 Fig. 2(a) presents the horizontally self-balanced test set-up. Two ends of the test set-up, A

110 and $\mathrm{B}$, were connected by four stock square hollow section beams with vertical baring 111 members along the whole length, which were designed to meet the cyclic loading 112 requirement and achieve the self-balancing. The axial load was applied by a $10,000 \mathrm{kN}$ 113 capacity actuator with the maximum stroke travel of $1000 \mathrm{~mm}$ at the end A in Fig. 2(a). The 114 other end B was equipped with the force sensor. The end A was fixed with the concrete 115 strong floor using eight expansion anchoring bolts, while the end B was free to deform in the 116 longitudinal direction but with the constraint in the lateral direction. The test specimen was 117 connected with the two bearings using 20 M36 bolts of grade S8.8 for one end [16]. Two 118 rolling bearings with the lifting jacks were positioned at each $1 / 3$ length to eliminate the 119 deflection of the member causing by its self-weight, as shown in Fig. 2(a).

120 Figs. 2(b) and 3 show the arrangements of displacement transduces and strain gauges 121 respectively. The strain gauges were mounted on the outer surface of the inner tube at the end

122 B (equipped with the force sensor) and the mid-length to obtain the longitudinal and hoop 123 strains, as shown in Figs. 3(a)-(c). Four linear variable displacement transducers (LVDTs) of 124 a large range and four digital dial-gauge (DDG) were used in the ends A and B respectively 125 to cover the possible maximum displacement during the cyclic test.

\subsection{Loading protocol}

127 A quasi-static loading scheme by displacement control was adopted according to AISC 341-

12816 [17]. On the basis of the Chinese code for seismic design of building (GB 50011-2010)

129 [18], the elastic-plastic storey drift angle requirement for steel structures is $1 / 50$ in seismicity 
regions of intensity 6.0-7.0. The relationship between the storey drift angle $\left(\theta_{s}\right)$ and the brace

131 deformation $(\Delta)$ is calculated by Eq. (1) [19]

$$
\Delta_{\mathrm{bm}}=\theta_{s} L \sin \alpha \cos \alpha
$$

133 where, $\Delta_{\mathrm{bm}}$ is the deformation corresponding the design storey drift; $\theta_{s}$ is the design storey drift; $\alpha$ is the diagonal angle of the bracing member; $L$ is the length of the bracing member. $\left(\Delta_{\mathrm{bm}}\right)$ can be calculated using Eq. (1), which is $150 \mathrm{~mm}$ for the test specimens in the case of $45^{\circ}$ diagonal angle $(\alpha)$. The value of deformation quantity at first significant yield of the specimen $\left(\Delta_{\text {by }}\right)$ can be calculated by $L f_{\mathrm{yi}} / E_{\mathrm{si}}$, where $f_{\mathrm{yi}}$ and $E_{\mathrm{si}}$ are the yield strength and the Young's modulus obtained from the material coupon tests. Fig. 4 presents the loading 140 protocol for the test. The loading rates for the elastic and plastic loading stages were 0.5 $141 \mathrm{~mm} / \mathrm{min}$ and $2.5 \mathrm{~mm} / \mathrm{min}$, respectively.

\section{3. Finite element model}

\section{3.1. General models}

144 Finite element analyses were conducted using ABAQUS/Explicit [20] to replicate the cyclic test of the 15-m SDT-BRB specimen and investigate the hysteretic response and behaviour deterioration evolution during the loading cycles. The full test specimen was modelled

147 because the contact between inner and outer tubes might occur non-symmetrically. To further

148 validate the developed FE model, the plain steel tribble-tube BRB test results from Zhang et al. [9] was also employed.

The three-dimensional solid elements, C3D8Rs, were adopted in FE models in order to capture the fracture phenomenon precisely, i.e. the processes of fracture initiation on the

152 surface and the propagation throughout the thickness. The hard contact model and Coulomb

153 friction model were employed in the normal and tangential directions, respectively, to 
154 simulate contact behaviour between the inner (slave surface) and outer (master surface) tubes.

155 All degrees of freedom on the end surfaces were coupled to the rigid plates. The axial loading

156 and the boundary conditions were applied to the reference points on the ridged plates, RP1

157 and RP2, respectively, which were in accordance with the test condition, as described in Fig.

1585.

159 The geometric imperfection was incorporated in the FE models by defining the global 160 imperfection based on the superposition of weighting eigenmode analysis data. The effects of 161 different imperfection values on the performance of the double-tube bracing members were 162 analysed. The results and discussions are presented in the following section. The amplitude of 163 global and local imperfections are $1.5 \mathrm{~mm}$ and $0.1 \mathrm{~mm}$, respectively.

164 The typical mesh of the FE model is shown in Fig. 5. In the thickness direction, the 165 element number was set to be three for both inner and outer tubes, while on the circumference, the element numbers of the inner and outer tubes were 88 and 36 respectively.

167 The refined mesh was used in the inner tube, where the regions were near the end of the 168 stiffeners, as marked in Fig. 5. Therefore, in the case of the outer tube, the element size 169 (longitudinal direction $\times$ circumferential direction) was $100 \mathrm{~mm} \times 50 \mathrm{~mm}$; while in the case 170 of inner tube, it was $50 \mathrm{~mm} \times 20 \mathrm{~mm}$ for the non-refined region and was $20 \mathrm{~mm} \times 20 \mathrm{~mm}$ for the refined region. The total element number was approximate130,600.

172 In the explicit analysis technique, despite the convergence problem will not occur, the 173 computational efficiency and accuracy should be particularly considered. Essentially, to 174 achieve the accurate simulation results using the explicit calculation method, the stable 175 increment should be small enough. However, this can lead to massive computational time in solving the quasi-static problems because of the relative long loading duration compared with

177 some dynamic events, such as impact and explosion simulation. There are two methods to 178 reduce the total computational time for the quasi-static simulation when using 179 ABAQUS/Explicit, which are described as followings: 
1) Speed up the load rate in the test to reduce the total loading time (by reducing the total time period for the displacement loading method or increasing the loading rate in the velocity loading method);

2) Present the mass scaling factor (MSF) to artificially increase the stable increment time. In this study, MSF was employed to reasonably reduce the computational time. It should be noted that these two methods might inevitably increase the inertial forces which significantly alters the solution when an impropriate value is adopted. Therefore, the sensitive study was conducted to achieve the balance between the computational accuracy and efficiency. The ratio of all kinetic energy (ALLIK) to all internal energy (ALLIE) was used to assess the feasibility of the adopted MSF values in the FE analysis [21,22], since

190 ALLIK/ALLIE indicated the stability of the simulation procedure. The load-displacement 191 hysteretic curves from the FE models with the MSF values of $10^{6}, 10^{7}, 10^{8}$, and $10^{9}$ are compared in Fig. 6(a). The largest MSF value, i.e. $10^{9}$, results the significantly unstable response during the initial loading steps. Moreover, the early fracture was predicted as the

194 MSF value increased, owing to the artificial dynamic effects caused by the impropriate 195 computational acceleration. Meanwhile, in the perspective of the dynamic effects, the 196 ALLIK-to-ALLIE ratios of the $10^{6}$-, $10^{7}$ - and $10^{8}$-MSF models were compared in Fig. 6(b).

197 The ratios for $10^{6}-, 10^{7}-$ MSF models are controlled under a low level during the entire 198 loading period. However, the model of $10^{6}$ MSF took more than three times computational 199 time (up to 7 days) than the one with $10^{7}$ MSF (approximately 42 hours). Therefore, the MSF 200 value of $10^{7}$ was adopted in this study after optimizing the computational accuracy and 201 efficiency.

\subsection{Plasticity model}

The mechanical behaviour of steel under cyclic loading was simulated by adopting the constitutive model with von-Mises yield criterion and the combined isotropic/kinematic 
$206 \mathrm{GPa}$ and 0.3 respectively. The isotropic hardening component is expressed in Eq. (2).

$$
\sigma_{0}=\left.\sigma\right|_{0}+Q_{\infty}\left(1-e^{-b \bar{\varepsilon}^{\mathrm{pl}}}\right)
$$

where $\left.\sigma\right|_{0}$ is the yield stress at zero plastic strain, $Q_{\infty}$ is the maximum change in size of yield

surface, $b$ is the rate of change of yield surface size with increasing plastic strain, $\bar{\varepsilon}^{-p l}$ is the equivalent plastic strain using Eq. (3)

$$
\bar{\varepsilon}^{p l}=\int_{0}^{t} \sqrt{\frac{2}{3} d \varepsilon^{p l}: d \varepsilon^{p l}} d t
$$

213 Eqs. (4) and (5)

$$
d \alpha_{k}=C_{k} \frac{1}{\sigma_{0}}(\sigma-\alpha) \cdot d \bar{\varepsilon}^{p l}-\gamma_{k} \alpha_{k} \cdot d \bar{\varepsilon}^{p l}
$$

$$
\alpha=\sum_{k=1}^{n} \alpha_{\mathrm{k}}
$$

216 where $\sigma_{0}$ is the size of the yield surface defined in Eq. (2), $C_{\mathrm{k}}$ is the $k^{\text {th }}$ initial kinematic

217 hardening moduli, $\gamma_{\mathrm{k}}$ is $k^{\text {th }}$ rate of decrease of $C_{\mathrm{k}}, \alpha$ is the overall backstress; $\alpha_{\mathrm{k}}$ is the $k^{\text {th }}$ back 218 stress;

Table 2 presents the constitutive model parameters calibrated according to ABAQUS 220 documentation [21] from material test.

\subsection{Fracture model}

The phenomenological ductile fracture model, Modified Mohr-Coulomb (MMC) model

224 triaxiality $(\eta)$ and Lode angle $(\theta)$ on the fracture initiation, which has been extensively 
verified in various metal material tests [23-25]. Meanwhile the ductile fracture of structural components under monotonic loading has been successfully predicted using MMC prediction model with a linear damage accumulation rule [22-23,26-27]. In the current study, MMC model with a nonlinear damage evolution [24,25] was adopted to the reversed or cyclic loading conditions.

\subsubsection{Definition of stress state variables}

231 A spherical coordinate system defined stress triaxiality $(\eta)$, Mises stress $(\bar{\sigma})$, and Lode angle $(\theta)$ was proposed by Bai and Wierzbicki [28] as a new stress space. It can be transformed

233 from the stress space in Cartesian coordinate system. The relations are given by Eqs. (6) 234 (13).

235 The first invariant of the stress tensor is defined by Eq. (6)

$$
I_{1}=\sigma_{1}+\sigma_{2}+\sigma_{3}
$$

237 The second and third invariants of the deviatoric stress tensor are expressed in Eqs. (7) and (8) respectively.

$$
\begin{aligned}
& J_{2}=\frac{1}{2} s_{i j} s_{i j} \\
& J_{3}=\frac{1}{3} s_{i j} s_{j k} s_{k i}
\end{aligned}
$$

241 The deviatoric stress tensor is described as Eq. (9)

$$
s_{i j}=\left[\begin{array}{ccc}
\sigma_{1}-\sigma_{m} & 0 & 0 \\
0 & \sigma_{2}-\sigma_{m} & 0 \\
0 & 0 & \sigma_{3}-\sigma_{m}
\end{array}\right]
$$

243 where $\sigma_{1}, \sigma_{2}, \sigma_{3}$ are the principle normal stresses; $\sigma_{m}$ in the mean value of normal stress $\frac{1}{3} I$.

244 The stress triaxiality and Lode angle are defined in Eqs. (10) and (11) respectively

$$
\eta=\frac{\sigma_{m}}{\bar{\sigma}}
$$




$$
\theta=\frac{1}{3} \arccos \left(\frac{27}{2} \frac{J_{3}}{\bar{\sigma}^{3}}\right)
$$

$$
\bar{\sigma}=\sqrt{3 J_{2}}
$$

where $\bar{\sigma}$ is Mises stress, $J_{2}$ and $J_{3}$ are the second and third deviatoric stress invariants respectively.

The normalized Lode angle, $\bar{\theta}$, is adopted in the MMC fracture prediction model [23] which is employed in the FE analysis in this study. The normalized Lode angle is presented as Eq. (13).

$$
\bar{\theta}=1-\frac{2}{\pi} \arccos \left(\frac{27}{2} \frac{J_{3}}{\bar{\sigma}^{3}}\right)
$$

\subsubsection{Phenomenological fracture model}

To efficiently detect the initiation of ductile fracture, the Mohr-Coulomb criterion has been transferred from a stress-based model to a strain-based model in a space of $\left(\bar{\varepsilon}^{p l}, \eta, \bar{\theta}\right)$ by Bai and Wierzbicki [28]. When a von Mises yield surface were adopted, the MMC fracture model is expressed in Eq. (14) [23].

$$
\bar{\varepsilon}_{f}=\left\{\frac{A}{c_{2}}\left[\sqrt{\frac{1+c_{1}^{2}}{3}} \cos \left(\frac{\bar{\theta} \pi}{6}\right)+c_{1}\left(\eta+\frac{1}{3} \sin \left(\frac{\bar{\theta} \pi}{6}\right)\right)\right]\right\}^{-\frac{1}{n}}
$$

260 where $\bar{\varepsilon}^{p l}$ is the equivalent fracture strain, calculated using Eq. (3); $\bar{\theta}$ is the normalized Lode 261 angle, in Eq. (13); $\eta$ is the stress triaxiality, in Eq. (10); $A$ and $n$, are the hardening exponent 262 and the amplitude respectively, which can be calibrated from the true stress-strain curve by 263 fitting Hollomon's [29] or Swift's [30] power laws; $c_{1}$ and $c_{2}$ are the friction coefficient and 264 the maximum shear strength in Mohr-Coulomb model, respectively.

265 A cut-off region in the negative stress triaxiality range, where fracture strain will go to infinity and therefore ductile fracture cannot occur, is defined in Eq. (15) [23]. 


$$
\sqrt{\frac{1+c_{1}^{2}}{3}} \cos \left(\frac{\bar{\theta} \pi}{6}\right)+c_{1}\left(\eta+\frac{1}{3} \sin \left(\frac{\bar{\theta} \pi}{6}\right)\right) \leq 0
$$

268 To calibrate the parameters, a comprehensive material test programme should be performed,

269 which is designed to cover the various stress triaxiality regimes at the onset of fracture

270 initiation using specially designed coupons. It is also required that the measurement can

271 obtain the true stress-strain evolution and recognise the onset of fracture initiation during the

272 whole loading history. This is a very complicated test and post-processing procedure. To

273 facilitate an effortless application of MMC model in structural analyses, a simplified

274 calibration procedure, based on the conventional tensile tests, for MMC model was proposed

275 and verified in previous studies [22, 26-27]. More detailed information for the simplified

276 calibration procedure can be found in $\mathrm{Xu}$ et al. $[22,26]$. The calibrated parameters in this

277 study are listed in Table 3.

$278 \quad 3.2 .3$ Nonlinear damage evolution rule

279 The linear damage accumulation rule was found to accurately predict material fracture

280 initiation in the cases of monotonic loading [23, 28]. However, the nonlinear damage

281 evolution itself and the load history effect should be considered in the cases of reversed

282 loading [24-25,31-32]. Therefore, the MMC model was extended to the reversed loading by

283 adopting a non-linear damage evolution rule [24]. Eqs. (16) and (17) account for the non-

284 linear damage accumulation and the load reversal effect respectively. The parameters value of 285 $c_{\mathrm{g}}, c_{\mathrm{h}}, \beta_{1}, \beta_{2}$ and $k_{\mathrm{h}}$ are presented in Table 3.

$$
F_{D}\left(D_{\mathrm{FI}}\right)=\left(c_{g} D_{\mathrm{FI}}+\frac{c_{g}}{e^{c_{g}}-1}\right)
$$

$$
F_{H}\left(D_{\mathrm{F}}, \mu_{h}\right)=\left(1+c_{h} \cdot D_{\mathrm{F}}^{\beta_{1}} \cdot \mu_{h}^{\beta_{2}}\right)^{k_{h}}
$$


where $c_{g}$ is the parameter of the extension function for nonlinear damage rule; $c_{h}, \beta_{1}, \beta_{2}$ and $k_{h}$ are the parameters of the extension function for load-change effects; $\mu_{\mathrm{h}}$ is in terms of the backstress and current stress tensors to capture the reverse loading effects given by Eq. (18)

$$
\mu_{h}=\int_{0}^{\bar{\varepsilon} p l}\left(1-\frac{\sigma_{i j}: \alpha_{i j}}{\left\|\sigma_{i j}\right\| \cdot\left\|\alpha_{i j}\right\|}\right) d \bar{\varepsilon}^{p l}
$$

where $\alpha$ and $\sigma$ are the backstress and current stress tensor respectively; $\bar{\varepsilon}^{p l}$ is equivalent plastic strain.

The incremental form of damage accumulation law is shown in Eq. (19). It indicated that ductile fracture initiates at the material point when $D_{\mathrm{FI}}$ is equal to unity.

$$
d D_{F I}=F_{D} \cdot F_{H} \frac{d \bar{\varepsilon}^{p l}}{\bar{\varepsilon}_{f}(\eta, \bar{\theta})}
$$

\subsubsection{Post-initiation softening}

When $D_{F I}$ reaches 1.0 , a post-initiation softening rule is used to quantify the material deterioration in a linear form between the material degradation and the equivalent plastic strain. In the FE models, the effective plastic displacement was adopted to avoid significant dependence of the mesh [21]. The post-initiation softening rule is expressed in Eqs. (20) and (21). It shows that the material point fails (deleting element in the Explicit solving technique) when $D_{\mathrm{PI}}$ is equal to unity.

$$
\begin{gathered}
E^{\prime}=\left(1-D_{P I}\right) \cdot E \text { and } \bar{\sigma}^{\prime}=\left(1-D_{P I}\right) \cdot \bar{\sigma} \\
d D_{P I}=\frac{L_{c}}{\bar{u}_{f}} \cdot d \bar{\varepsilon}^{p l}
\end{gathered}
$$

where $D_{P I}$ is the post-initiation degradation indicator, $L_{\mathrm{c}}$ is the characteristic length of the element and $\bar{u}_{f}^{p l}$ is the effective plastic displacement.

The MMC model (Eq. (14)) with the nonlinear damage accumulation rule (Eqs. (16) (19)) was incorporated into the finite element analysis using user subroutine, VUSDFLD. The 
310 element deletion provided in ABAQUS/Explicit is activated when $D_{P I}$ reaches 1.0. This can

311 simulate the visual fracture cracking.

\section{4. Test results and FE model validation}

\section{4.1. Test results}

314 The failure mode of the $15 \mathrm{~m}$ test specimen is shown in Figs. 7(a) and (b). The inner tube of

315 the test specimen fractured at the tips of the inner stiffeners after several inelastic loading 316 cycles. The straight seam welds of inner and outer tubes were visually undamaged after the

317 test. No global buckling occurred during the test. Local buckling was only observed at the 318 fracture region. The premature fracture can be attributed to the accumulated localized plastic strain which is mainly induced by the stress concentration at the tips of the stiffeners. Therefore, to achieve the satisfactory performance of the stiffened double-tube bracing members, the influence of the dimensions and arrangements of the stiffeners were investigated in the parametric study.

The load-displacement curve of test specimen is shown in Fig. 8. The fracture onset is indicated in the curve during the compressive loading excursion. The behaviour of inner tube was monitored by the strain gauges since it was unable to be observed visually during test. The arrangement and records of the strain gauges are shown in Figs. 3 and 9 respectively. Fig. 9(a) presents the average longitudinal strain evolution at the end and mid-sections, where SGE and SGM refer the strain gauges mounted on the end and mid-section. The endstiffeners have minor effects on the initial stiffness, while the discrepancies of the stiffness are found between the end and mid-sections owing to additional stiffeners. The longitudinal stain readings of SGEs 1-3 on the end section are presented in Fig. 9(b). It indicates the uniformly distributed elastic stresses of the un-stiffened region of the inner tube beyond the outer tube, where it is designed not to be yielded or buckled. Fig. 9(c) shows the average hoop strain evolutions at the end and mid-sections. The stable and saturated hoop strain 
hysteretic curves are developed at the mid-section, demonstrating that no global and local buckling occurred at the mid-length.

The characteristics of hysteretic curve of the test specimen, such as adjustment factors for the compressive-capacity and strain hardening, hysteretic shape and energy dissipated are presented in Tables 4 - 5 and discussed in the following section.

\subsection{Validation of FE model}

The comparison of the force-displacement curves between the experimental and numerical results is shown in Fig. 8. The fracture processes of the FE result, i.e. initiation and cracking throughout the thickness, are presented. As anticipated, premature fracture initiated at the end of the inner stiffeners where the sudden change of the local stiffness existed. This sudden change of stiffness resulted in the stress concentration and local buckling during the periodic loading history, as shown in Figs. 7(b) and (c). To further validate the established FE models in capturing the fracture onset of plain steel BRBs, the test results of tri-tube BRB specimens from Zhang, et. al [9] was adopted for comparisons. The specimens which failed at fracture were replicated in the numerical simulation. The calibrated parameters for the steel plasticity and fracture models are listed in Tables 2 and 3. The force-displacement curves with fracture initiation marked are compared in Fig. 10. Furthermore, the hysteretic curves calculated from the developed FE models are also compared with those calculated from non-fracture associated models, as shown in Figs. 11(a) and (b). The FE models without fracture criterion would go further and complete the whole specified loading protocols without any occurrence of failure, i.e. local buckling, global buckling and deteriorations of the strength and stiffness. These non-fracture associated FE models would overestimate the ductility capacity and dissipated energy, leading to inaccurate cyclic structural behaviour. The comparisons also demonstrate the importance and necessity of incorporating the ELCF fracture model in the numerical simulation of BRB. 
The failure modes of test specimens in the present and previous studies are compared in

361 Figs. 7 and 10 respectively. The FE models are capable of predicting the fracture initiation.

362 Moreover, the comparison in Fig. 7(b) also demonstrates the FE model can capture the

363 buckling-induced fracture and stress-concentration-induced fracture. The equivalent plastic

364 strain distribution at the onset of fracture initiation is presented in Fig. 7(c). It indicates that

365 the fracture initiates from the inner surface of the inner tube at the critical positions where the significant stress concentration exists.

The evolution of accumulation damage, $D_{\mathrm{FI}}$, versus stress triaxiality and normalized the loading history, the stress triaxiality and normalized Lode angle approximately of the element ranged from -0.6 to 0.6 and -0.8 to 0.8 respectively. This also indicated that the element was under multi-axial stress states. In addition, the equivalent plastic strain increased significantly at the last cycle to fracture initiation.

the applicability of the adopted fracture model in the member-level ELCF fracture simulation.

375 It also demonstrates that the newly developed FE models can accurately simulate the hysteretic response and fracture occurrence of the stiffened double-tube BRB under ELCF.

\section{5. Parametric studies}

378 The parametric studies were conducted to further assess the influence of the inner stiffeners, material property, gap size and imperfection on the cyclic behaviour of the double-tube BRBs.

The test specimen was considered as the benchmarked specimen, labelled as OT550-25IT480-14-GP10-L15, where OT, IT, GP and L refer to the outer tube, inner tube, gap and length respectively; the numbers following OT and IT represent the tube diameter (i.e. 550 
384 (i.e. $25 \mathrm{~mm}$ for the outer tube and $14 \mathrm{~mm}$ for the inner tube); the numbers following GP and

385 L are the gap size (i.e. $10 \mathrm{~mm}$ ) and member length (i.e. $15 \mathrm{~m}$ ).

386

387 As observed in the test, the fracture initiated from the inside surface of the inner tube at the stiffener tips(see Fig. 7(c)). Therefore, the different arrangements of the stiffeners are

\subsection{Effect of material property}

403 Three different materials for the inner tube, i.e. the low-yield-point steel (LYP225 [33]), the 404 mild steel (Q235 steel) and the stainless steel (EN 1.4301 [34]), are employed to evaluate the influences of different material properties. The parameters of plasticity and fracture models are calibrated from the material tests [33-34] as presented in Tables 2 and 3. The material investigated using the established FE models, with the purpose to mitigate the stress concentration level. Three cross-sections are proposed for the comparison, i.e. eight-stiffener (ES) section, four-stiffener (FS) section and changeable-thickness (CT) section. The dimensions of the stiffeners and tube-wall thickness at the end are designed based on the criterion that the stiffened region remains elastic without local buckling during the entire loading history. The proposed sections are shown in Fig. 13(a). The hysteretic responses of three kinds of sections are presented in Fig. 13(b). It demonstrates that different stiffener arrangements have minor influence on the hysteretic curves; however, significant discrepancies are found on the onset of fracture. For the CT section series, the stress concentration is mitigated because of the smooth transition zone between the stiffened and effective regions. For the FS section series, the longer distance between two hot-spots of stress concentration can also mitigate the whole section deterioration compared with the ES section. property of the outer tube is keep the same as the test specimen. The force-displacement 
curves from the FE analyses are normalised by their yield strengths to facilitate the

409 comparison between the materials having different yield strengths. Fig. 13(a) shows that in

410 the case of ES section models (in the same dimension as the test specimen) the low yield

411 point steel can achieve most saturated hysteretic loops and reach the $1 \%$ deformation.

412 However, owing to the dominant influence of the stress concentration effect caused by the

413 end-stiffeners, the FE models with these three materials fail at the same cycle. Fig. 13(b)

414 presents that in the case of changeable-thickness section models, OT550-25-IT480-14-GP10-

415 L15-CT, the FE models with LYP 225 and EN 1.4301 fractured at the second cycle of 1/75L

416 deformation, which exhibit better ductility than the model with Q235 material. Furthermore,

417 as seen in Figs. 13(a) and (b), for the FE models with material EN 1.4301, both tensile and

418 compressive strengths cannot reach the nominal yield strength until $1 \%$ deformation. The

419 comparisons of adjustment factors for the compressive-capacity, strain hardening, hysteretic

420 shape and energy dissipated between each material are discussed in the following section.

\subsection{Effect of gap and global imperfections}

The gap size between the outer and inner tubes is a primary parameter for the design, fabrication and installation. The clearance is essential for the transfer of the lateral force from the inner tube to the outer tube while preventing the load transfer in the longitudinal direction. The small clearance would cause increasing difficulties in the fabrication and installation processes; in the case of the lager clearance, the fluctuations in the hysteretic curves were reported [8]. Therefore, the influence of the gap size on the hysteretic response are evaluated for the FE models with different end-stiffener arrangements. The geometry properties of the FE models with different gap values are listed in Table 6. The member

430 length and dimensions of the inner tubes keep constant, while the diameter and thickness of the outer tube change in accordance with the gap size to keep an identical confinement ratio 
$432\left(F_{\text {cri }} / f_{\mathrm{si}} A_{\text {si }}\right)$ for all parametric models, where $F_{\text {cri }}$ is the Euler critical force calculated using Eq. 433 (22).

$$
F_{\text {cri }}=\frac{\pi^{2} E_{\mathrm{so}} I_{\mathrm{so}}}{(K L)^{2}}
$$

where $E_{\mathrm{so}}$ is the Young's modulus of the outer tube, $I_{\mathrm{so}}$ is the moment of inertia of the cross section of the outer tube, $K$ is the column effective length factor and $L$ is the member length.

The results from the FE analyses are presented in Fig. 14. The large gap size, i.e. $20 \mathrm{~mm}$, has effects on the hysteretic response where fluctuations are observed. There is negligible influence on the stable and saturated properties of the hysteretic curves for the $5 \mathrm{~mm}$ and 10 mm gap series, as shown in Figs. 14(a) and (b). Since the stress concentration is the main failure mode for the ES series, the influence of the gap size on the fracture initiation is less important. In the case of the CT series, the larger gap leads to the earlier fracture initiation especially for the model with a $20 \mathrm{~mm}$ gap as shown in Fig. 14(b).

The initial global imperfection of the inner tube is unavoidable during the manufacturing and installation processes of a full-scale BRB. Therefore, the hysteretic response and the fracture initiation for the FE models with the initial global imperfection values ranging from $L / 10000$ to $L / 2000$ are compared in Fig. 15 . The imperfection influence on BRB models with different end sections, i.e. eight-stiffener and changeable-thickness sections, are investigated and the force-deformation curves and fracture onsets are compared, as shown in Figs. 15. It should be noted that, the imperfection value of $L / 2000(7.5 \mathrm{~mm})$ for the $5 \mathrm{~mm}$ gap series is larger than the gap size and is excluded in the parametric study. Figs 15(a) and (b) demonstrate that the global imperfection has negligible influence on the hysteretic response and the fracture initiation.

Therefore, the gap size should be limited to $20 \mathrm{~mm}$ to achieve the stable hysteretic response. The gap size ranging from $5 \mathrm{~mm}$ to $10 \mathrm{~mm}$ is suggested considering the fabrication and installation based on the parametric study. 
458

459

460

461

462

463

464

465

466

467

468

469

470

471

472

473

474

475

476

477

478

The compressive-strength adjustment factor, $\beta$, accounting for the tension-compression symmetry property and the tension strain hardening adjustment factor, $\omega$, are calculated according to AISC 341-16 [17] using Eqs. (23) and (24).

$$
\begin{gathered}
\beta=\frac{F_{\mathrm{c}, \text { max }}}{F_{\mathrm{t}, \text { max }}} \\
\omega=\frac{F_{\mathrm{t}, \text { max }}}{f_{\mathrm{ysi}} A_{\mathrm{si}}}
\end{gathered}
$$

where $F_{\mathrm{c}, \max }$ and $F_{\mathrm{t}, \max }$ are respectively the maximum compressive and tensile forces; $f_{\mathrm{ysi}}$ is the yield strength of inner tube; $A_{\mathrm{si}}$ is the section area of inner tube.

The calculated adjustment factors, i.e. $\beta$ and $\omega$, for the FE models with various material properties and stiffener arrangements aforementioned are listed in Table 4. At the cycle prior to fracture, the values of $\beta$ range from 1.01 to 1.08 , which satisfies the requirement in AISC seismic provisions [17] (i.e. $\beta \leqslant 1.3$ ). The values of $\omega$ range from 0.91 to 1.32 , and the ES model in EN 1.4301 fail to reach the yield strength. Despite stainless steel can possess large elongation before fracture (more than 50\% [34]), the performance of bracing members benefits little from this merit.

The shape factor, $\chi$, is adopted to assess the pinching effect of the hysteretic curves as defined schematically in Fig. 16 [13]. The average values of $\chi$ at each loading amplitude are calculated and presented in Table 5. The shape factor $\chi$ gradually increases as the amplitude, indicating that the hysteresis loops can be more saturated at a lager amplitude step. The FE models with LYP225 achieve the highest $\chi$ values among the compared materials at a same loading amplitude; while the models with EN 1.4301 fail to reach 3.0 until the amplitude of 1/75L. In addition, according the Chinese seismic design provision (GB5001-2010) [18], the 
479 equivalent ratio of critical viscous damping ( $\xi_{\mathrm{eq}}$ ) of BRBs is defined in Eq. (25) which is $\frac{1}{2 \pi}$ 480 time of the shape factor $\chi$. The SDT-BRBs could achieve a high value $(>0.3)$ and the 481 maximum value is obtained by the FE model OT550-25-IT480-14-GP10-L15-CT with 482 LYP225.

$$
\xi_{\mathrm{eq}}=\frac{S_{\mathrm{FBC}}+S_{\mathrm{EBC}}}{2 \pi\left(S_{\triangle \mathrm{ODF}}+S_{\triangle \mathrm{OAE}}\right)}
$$

The values of the total hysteretic energy dissipated for each model are compared in Table

4. The normalized value is adopted to facilitate the comparison among models with different material properties. The CT model with LYP225 achieves the highest normalized value, and 487 the ES model with EN 1.4301 behaves least favourably owing to the deficient ductility, low adjustment factor and small shape factor.

\section{Conclusions}

490

A stiffened double-tube buckling-restrained brace was proposed for boiler steel plant structures. The full-scale experiment was conducted on the $15 \mathrm{~m}$ bracing member to investigate the performance of the proposed BRB in the practical structures. A finite element model was established with material fracture criterion to further evaluate the hysteretic behaviour and to accurately predict the fracture failure. The parametric study was carried out on some practical concerning issues, i.e. the effects of the stiffener arrangement, material property, gap size and imperfection. Major findings obtained from this study are as follows:

1) The hysteretic loops prior to failure was stable and saturated. No negative effects of the manufacturing processes of cold-form and straight welding on the hysteretic response of the large-scale BRB, i.e. a $15 \mathrm{~m}$ test specimen. The premature fracture initiated at the inside surface of the inner tube at the stiffener tips where the severe 
stress concentration existed, leading to failure of the test specimen. No global buckling occurred during the loading cycles.

2) The FE models incorporating a material fracture criterion and a damage evolution law were developed and validated by the test results from different experimental programmes. The FE models without a material fracture criterion would probably overestimate the ductility capacity of BRBs. The comparison of different FE models also manifested the accuracy and reliability of the model in predicting the behaviour deterioration and failure onset.

3) Based on the parametric study, both methods of reducing the stress concentration achieve a stable hysteretic behaviour.

\section{Acknowledgments}

\section{References}

[1] Takeda T, Takemoto Y, Furuya Y. An experimental study on moment frame with steel

[2] Wakabayashi M, Nakamura T, Katagihara A, et al. Experimental study on the elastoplastic behavior of braces enclosed by precast concrete panels under horizontal cyclic loading-Parts 1 \& 2. Annual meeting, AIJ 1973; 6: 121-122. [in Japanese]

[3] Mochizuki S, Murata Y, Andou N, et al. An experimental study on the buckling behaviour of steel braces with concentric axial forces Part 1, Annual Meeting AIJ, 1979; 54: 1623-1624. [in Japanese]

[4] Sabelli R, Mahin S, Chang C, Seismic demands on steel braced frame buildings with buckling-restrained braces, Engineering Structures 2003; 25: 655-666. 
[5] Black C, Makris N, Aiken I. Component testing, seismic evaluation and characterization of buckling-restrained braces. Journal of Structural Engineering 2004;130(6): 880-894.

[6] Kim J, Choi H. Behavior and design of structures with buckling-restrained braces. Engineering Structures 2004; 26(6): 693-706.

[7] Takeuchi T, Hajjar J Matsui R, et al. Local buckling restraint condition for core plates in buckling restrained braces. Journal of Constructional Steel Research 2010; 66(2): 139149.

[8] Heidary-Torkamani H, Maalek S. Conceptual numerical investigation of all-steel Tubein-Tube buckling restrained braces. Journal of Constructional Steel Research 2017; 139: 220-235.

[9] Zhang D, Nie X, Pan P, et al. Experimental study and finite element analysis of a buckling-restrained brace consisting of three steel tubes with slotted holes in the middle tube. Journal of Constructional Steel Research 2016; 124: 1-11.

[10] Kuwahara S, Tada M, Yoneyama T, et al. A study on stiffening capacity of double tube members. Journal of Structural and Construction Engineering 1993; 445 (3): 151-158. [in Japanese]

[11] Suzuki T, Ogawa T, Ogasawara T. A study on inelastic buckling of circular tubes under axial compression with outer constraints. Journal of Structural and Construction Engineering 1994; 458(4): 137-143. [in Japanese]

[12] Deng X, Chen Z, Zhou Y. Experimental study on performance of perforating triple-steel tube buckling-restrained brace. Journal of Building Structures 2012. 33 (6): 42-49. [In Chinese]

[13] Qu B, Liu X, Hou H, et al. Testing of buckling-restrained braces with replaceable steel

[14] Aguaguiña M, Zhou Y, Gong S, et al. Application of Buckling-Restrained Braces in the

[15] Chen S, Lu Z, Li H, et al. Application of buckling restrained brace and high-strength Seismic Design of a Thermal Power Plant in China. In Key Engineering Materials 2018; 763: 1017-1024. steel in steel frame structure of thermal power plant. Progress in Steel Building Structures 2013, 15(5): 41-47. [In Chinese]

[16] GB/T 1228-2016. High strength bolts with large hexagon head for steel structures. Standards Press of China, Beijing, China; 2006. [In Chinese]

[17] AISC 341. Seismic provisions for structural steel buildings. AISC-341, Chicago, 2016.

[18] GB 50011-2010. Code for Seismic Design of Buildings. China Architecture \& building Press, Beijing, 2010. [In Chinese]

[19] Iwata M, Murai M. Buckling-restrained brace using steel mortar planks; performance 
evaluation as a hysteretic damper. Earthquake engineering \& structural dynamics 2006; 35(14): 1807-1826.

566

[20] ABAQUS 6.14 [Computer software]. Dassault Systems, Waltham, MA, USA; 2014.

[21] Hibbitt HD, Karlsson BI, Sorensen P. ABAQUS documentation collection. Ver. 6.14, USA; 2014.

[22] Xu F, Chen J, Chan TM. Mechanical behaviour of concrete-filled CHS connections subjected to in-plane bending. Engineering Structures 2017; 148: 101-112.

[23] Bai YL, Wierzbicki T. Application of extended Mohr-Coulomb criterion to ductile fracture. International Journal of Fracture 2010; 161(1): 1-20.

[24] Bai YL. Fracture of 1045 steel under complex loading history. AIP Conf. Proc. Vol. 1383, 58-746: 2011.

[25] Algarni M, Choi Y, Bai YL. A unified material model for multiaxial ductile fracture and extremely low cycle fatigue of Inconel 718. International Journal of Fatigue 2017; 96: $162-177$.

[26] Xu F, Chen J, Chan TM. Numerical analysis and punching shear fracture based design of longitudinal plate to concrete-filled CHS connections. Construction and Building Materials 2017; 156: 91-106.

[27] Xu F, Chen J, Jin WL. Punching shear failure of concrete-filled steel tubular CHS connection. Journal of Constructional Steel Research 2016; 124: 113-121.

[28] Bai YL, Wierzbicki T. A new model of metal plasticity and fracture with pressure and Lode dependence. International journal of plasticity 2008; 24(6): 1071-1096.

[29] Hosford W. A generalized isotropic yield criterion. J Appl Mech 1972; 39:607.

[30] Hollomon JH. Tensile Deformation. Transactions of the Metallurgical Society of AIME 1945; 162: 268-290.

[31] Kanvinde A, Deierlein G. Cyclic void growth model to assess ductile fracture initiation in structural steels due to ultra low cycle fatigue. Journal of engineering mechanics 2007; 133(6): 701-712.

[32] Wen H, Mahmoud H. New model for ductile fracture of metal alloys. II: Reverse loading. Journal of Engineering Mechanics 2015; 142(2): 04015089.

[33] Shi Y, Wang J, Wang Y, Pan P, et al. Mechanical performance of low-yield-point steel LYP225 under cyclic loading. Journal of Southeast University (Nature Science Edition) 2014. 44(6): 1260-1265.

[34] Chen J, Young B. Stress-strain curves for stainless steel at elevated temperatures. Engineering Structures 2006, 28(2): 229-239. 
599 List of Figure Captions

600 Figure 1. Test specimen

601 Figure 2. Test setup

602 Figure 3. Location of the strain gauges

603 Figure 4. Loading protocol

604 Figure 5. Finite element model

605 Figure 6. Comparison of hysteretic responses from test and simulation

606 Figure 7. Failure mode of the test specimen and FE model

607 (Eight times magnified deformations at the cross-section)

608 Figure 8. Comparison of hysteretic responses from test and simulation

609 Figure 9. Average values of measured strains

610 Figure 10. Comparison of hysteretic responses from test and simulation [9]

611 Figure 11. Comparison of hysteretic responses from different FE models

612 Figure 12. Relationship of fracture index with (a) stress triaxiality (b) normalized Lode angle

613 Figure 13. Effects of the stiffener arrangements

614 Figure 14. Effects of material properties

615 Figure 15. Effects of gap size

616 Figure 16. Effects of global imperfections

617 Figure 17. Schematic view for the definition of $\chi$ 


\section{List of Table Captions}

619 Table 1. Measured material properties

620 Table 2. Mechanical properties and parameters of constitutive model for materials

621 Table 3. Parameters of the fracture model and damage rule used in FE models

622 Table 4. Summary of strain hardening and compressive strength adjustment factors

623 Table 5. Summary of $\chi$ and $\xi_{\text {eq }}$ at each amplitude

624 Table 6. Dimensions for the parametric FE models with different gap sizes 
Table 1. Measured material properties

\begin{tabular}{cccc}
\hline Regions & $\begin{array}{c}f_{\mathrm{y}} \\
\left(\mathrm{N} / \mathrm{mm}^{2}\right)\end{array}$ & $\begin{array}{c}f_{\mathrm{u}} \\
\left(\mathrm{N} / \mathrm{mm}^{2}\right)\end{array}$ & $\begin{array}{c}E \\
\left(\mathrm{kN} / \mathrm{mm}^{2}\right)\end{array}$ \\
\hline Stiffener & 259.3 & 390.6 & 198.3 \\
Outer tube & 260.3 & 384.0 & 202.7 \\
Inner tube & 255.3 & 383.7 & 207.0 \\
\hline
\end{tabular}


Table 2. Mechanical properties and parameters of constitutive model for materials

\begin{tabular}{|c|c|c|c|c|c|c|c|c|}
\hline Material types & $\begin{array}{c}E_{\mathrm{s}} \\
(\mathrm{GPa})\end{array}$ & $\begin{array}{c}f_{\mathrm{y}} \\
(\mathrm{MPa})\end{array}$ & $\begin{array}{c}f_{\mathrm{u}} \\
(\mathrm{MPa})\end{array}$ & $\begin{array}{c}\left.\sigma\right|_{0} \\
(\mathrm{MPa})\end{array}$ & $\begin{array}{c}Q_{\infty} \\
(\mathrm{MPa})\end{array}$ & $b$ & $\begin{array}{c}C_{\mathrm{k}} \\
(\mathrm{MPa})\end{array}$ & $\gamma_{\mathrm{k}}$ \\
\hline \multirow{3}{*}{ Q235 } & \multirow{3}{*}{207.0} & \multirow{3}{*}{255.3} & \multirow{3}{*}{383.7} & \multirow{3}{*}{232.3} & \multirow{3}{*}{21} & \multirow{3}{*}{1.2} & 55189 & 986.0 \\
\hline & & & & & & & 5000 & 55.0 \\
\hline & & & & & & & 3000 & 84.0 \\
\hline \multirow{4}{*}{ LYP225 [33] } & \multirow{4}{*}{195.1} & \multirow{4}{*}{221.0} & \multirow{4}{*}{327.0} & \multirow{4}{*}{165.0} & \multirow{4}{*}{53} & \multirow{4}{*}{5.0} & 62105 & 1611.0 \\
\hline & & & & & & & 4986 & 413.0 \\
\hline & & & & & & & 1978 & 95.0 \\
\hline & & & & & & & 701 & 3.0 \\
\hline \multirow{3}{*}{ EN 1.4301 [34] } & \multirow{3}{*}{182.5} & \multirow{3}{*}{417.3} & \multirow{3}{*}{702.5} & \multirow{3}{*}{184.3} & \multirow{3}{*}{21} & \multirow{3}{*}{1.2} & 39731 & 698.0 \\
\hline & & & & & & & 39284 & 248.0 \\
\hline & & & & & & & 2429 & 2.3 \\
\hline \multirow{3}{*}{ Q235 [9] } & \multirow{3}{*}{206.0} & \multirow{3}{*}{422} & \multirow{3}{*}{639} & \multirow{3}{*}{422} & \multirow{3}{*}{--} & \multirow{3}{*}{--} & 9000 & 250.0 \\
\hline & & & & & & & 2000 & 150.0 \\
\hline & & & & & & & 4000 & 100.0 \\
\hline
\end{tabular}


Table 3. Parameters of the fracture model and damage rule used in FE models

\begin{tabular}{|c|c|c|c|c|c|c|c|c|c|}
\hline Material types & $\begin{array}{c}A \\
(\mathrm{MPa})\end{array}$ & $n$ & $c_{1}$ & $\begin{array}{c}c_{2} \\
(\mathrm{MPa})\end{array}$ & $c_{\mathrm{g}}$ & $c_{\mathrm{h}}$ & $\beta_{1}$ & $\beta_{2}$ & $k_{\mathrm{h}}$ \\
\hline Q235 & 623.6 & 0.182 & 0.12 & 287.8 & -6 & 5.5 & 2 & 2 & 0.6 \\
\hline LYP225 [33] & 570.9 & 0.232 & 0.12 & 245.3 & -6 & 5.5 & 2 & 2 & 0.6 \\
\hline EN 1.4301 [34] & 1361.5 & 0.313 & 0.12 & 526.9 & -6 & 5.5 & 2 & 2 & 0.6 \\
\hline Q235 [9] & 745.4 & 0.209 & 0.12 & 377.8 & -6 & 5.5 & 2 & 2 & 0.6 \\
\hline
\end{tabular}


Table 4. Summary of strain hardening and compressive strength adjustment factors

\begin{tabular}{|c|c|c|c|c|c|c|c|c|c|}
\hline & \multirow[b]{2}{*}{ Specimens } & \multirow[b]{2}{*}{ Remarks } & \multirow[b]{2}{*}{$\begin{array}{c}\text { Material } \\
\text { types }\end{array}$} & \multirow{2}{*}{$\begin{array}{l}\text { Number } \\
\text { of cycles } \\
\text { to failure }\end{array}$} & \multicolumn{2}{|c|}{$\beta$} & \multicolumn{2}{|c|}{$\omega$} & \multirow{2}{*}{$\begin{array}{l}\text { Total normalized } \\
\text { hysteretic energy } \\
\text { absorption } \\
E_{\text {total }} /\left(f_{\mathrm{yi}} A_{\mathrm{si}} L\right)\end{array}$} \\
\hline & & & & & $\begin{array}{l}\text { Before } \\
\text { fracture }\end{array}$ & $\begin{array}{l}1 \text { st cycle } \\
\text { at } 1 / 100 L\end{array}$ & $\begin{array}{l}\text { Before } \\
\text { fracture }\end{array}$ & $\begin{array}{l}1 \text { st cycle } \\
\text { at } 1 / 100 L\end{array}$ & \\
\hline Test & $\begin{array}{l}\text { OT550-25- } \\
\text { IT480-14- } \\
\text { GP10-L15 }\end{array}$ & $\begin{array}{c}\text { Test } \\
\text { specimens }\end{array}$ & Q235 & $\begin{array}{c}\text { 1st cycle } \\
\text { at } \\
1 / 100 \mathrm{~L}\end{array}$ & 1.01 & -- & 0.03 & -- & 0.03 \\
\hline \multirow{7}{*}{$\begin{array}{l}\text { Para. } \\
\text { study }\end{array}$} & $\begin{array}{c}\text { OT550-25- } \\
\text { IT480-14- } \\
\text { GP10-L15-ES }\end{array}$ & \multirow{3}{*}{$\begin{array}{l}\text { with eight } \\
\text { stiffeners } \\
(\mathrm{ES}) \text { at } \\
\text { both ends }\end{array}$} & Q235 & $\begin{array}{l}\text { 1st } \\
\text { cycle at } \\
1 / 100 \mathrm{~L}\end{array}$ & 1.02 & -- & 0.04 & -- & 0.04 \\
\hline & $\begin{array}{c}\text { OT550-25- } \\
\text { IT480-14- } \\
\text { GP10-L15-ES }\end{array}$ & & $\begin{array}{c}\text { LYP225 } \\
\text { [33] }\end{array}$ & $\begin{array}{c}1 \text { st } \\
\text { cycle at } \\
1 / 100 \mathrm{~L}\end{array}$ & 1.03 & -- & 0.04 & -- & 0.04 \\
\hline & $\begin{array}{c}\text { OT550-25- } \\
\text { IT480-14- } \\
\text { GP10-L15-ES }\end{array}$ & & $\begin{array}{c}\text { EN } \\
1.4301 \\
{[34]}\end{array}$ & $\begin{array}{c}1 \text { st } \\
\text { cycle at } \\
1 / 100 \mathrm{~L}\end{array}$ & 1.01 & -- & 0.02 & -- & 0.02 \\
\hline & $\begin{array}{c}\text { OT550-25- } \\
\text { IT480-14- } \\
\text { GP10-L15-FS }\end{array}$ & $\begin{array}{l}\text { with four } \\
\text { stiffeners } \\
\text { (FS) at } \\
\text { both ends }\end{array}$ & Q235 & $\begin{array}{l}1 \text { st cycle } \\
\text { at } 1 / 75 \mathrm{~L}\end{array}$ & 1.04 & 1.07 & 0.12 & 1.29 & 0.12 \\
\hline & $\begin{array}{c}\text { OT550-25- } \\
\text { IT480-14- } \\
\text { GP10-L15-CT }\end{array}$ & \multirow{3}{*}{$\begin{array}{l}\text { with } \\
\text { gradually } \\
\text { changed } \\
\text { thickness } \\
(\mathrm{CT}) \text { at } \\
\text { both ends }\end{array}$} & Q235 & $\begin{array}{l}1 \text { st cycle } \\
\text { at } 1 / 75 \mathrm{~L}\end{array}$ & 1.05 & 1.02 & 0.12 & 1.29 & 0.12 \\
\hline & $\begin{array}{c}\text { OT550-25- } \\
\text { IT480-14- } \\
\text { GP10-L15-CT }\end{array}$ & & $\begin{array}{c}\text { LYP225 } \\
\text { [33] }\end{array}$ & $\begin{array}{l}\text { 2nd } \\
\text { cycle at } \\
1 / 75 \mathrm{~L}\end{array}$ & 1.08 & 1.07 & 0.18 & 1.12 & 0.18 \\
\hline & $\begin{array}{c}\text { OT550-25- } \\
\text { IT480-14- } \\
\text { GP10-L15-CT }\end{array}$ & & $\begin{array}{c}\text { EN } \\
1.4301 \\
{[34]}\end{array}$ & $\begin{array}{l}\text { 2nd } \\
\text { cycle at } \\
1 / 75 \mathrm{~L}\end{array}$ & 1.06 & 1.05 & 0.13 & 0.99 & 0.13 \\
\hline
\end{tabular}


Table 5. Summary of $\chi$ and $\xi_{\text {eq }}$ at each amplitude

\begin{tabular}{|c|c|c|c|c|c|c|c|c|c|c|}
\hline & \multirow{2}{*}{ Specimens } & \multirow{2}{*}{ Remarks } & \multirow{2}{*}{$\begin{array}{l}\text { Materia } \\
1 \text { types }\end{array}$} & \multirow{2}{*}{$\begin{array}{l}\text { Number of } \\
\text { cycles to } \\
\text { failure }\end{array}$} & \multicolumn{3}{|c|}{$\begin{array}{c}\chi \\
\text { (defined in Fig. 17) } \\
\end{array}$} & \multicolumn{3}{|c|}{$\begin{array}{c}\xi_{\text {eq }} \\
\text { (defined in Eq. 25) }\end{array}$} \\
\hline & & & & & $1 / 200 L$ & $1 / 100 L$ & $1 / 75 L$ & $1 / 200 L$ & $1 / 100 L$ & $1 / 75 \mathrm{~L}$ \\
\hline Test & $\begin{array}{l}\text { OT550-25- } \\
\text { IT480-14- } \\
\text { GP10-L15 }\end{array}$ & $\begin{array}{c}\text { Test } \\
\text { specimens }\end{array}$ & Q235 & $\begin{array}{c}1 \text { st cycle at } \\
1 / 100 L\end{array}$ & 3.34 & -- & -- & 0.53 & -- & -- \\
\hline \multirow{7}{*}{$\begin{array}{l}\text { Para. } \\
\text { study }\end{array}$} & $\begin{array}{l}\text { OT550-25- } \\
\text { IT480-14- } \\
\text { GP10-L15-ES }\end{array}$ & \multirow{3}{*}{$\begin{array}{l}\text { With eight } \\
\text { stiffeners } \\
\text { (ES) at } \\
\text { both ends }\end{array}$} & Q235 & $\begin{array}{l}\text { 1st cycle at } \\
1 / 100 \mathrm{~L}\end{array}$ & 3.14 & -- & -- & 0.50 & -- & -- \\
\hline & $\begin{array}{l}\text { OT550-25- } \\
\text { IT480-14- } \\
\text { GP10-L15-ES }\end{array}$ & & $\begin{array}{c}\text { LYP22 } \\
5[33]\end{array}$ & $\begin{array}{c}1 \text { st cycle at } \\
1 / 100 L\end{array}$ & 3.43 & -- & -- & 0.55 & -- & -- \\
\hline & $\begin{array}{c}\text { OT550-25- } \\
\text { IT480-14- } \\
\text { GP10-L15-ES }\end{array}$ & & $\begin{array}{c}\text { EN } \\
1.4301 \\
{[34]}\end{array}$ & $\begin{array}{c}\text { 1st cycle at } \\
1 / 100 L\end{array}$ & 2.30 & -- & -- & 0.37 & -- & -- \\
\hline & $\begin{array}{l}\text { OT550-25- } \\
\text { IT480-14- } \\
\text { GP10-L15-FS }\end{array}$ & $\begin{array}{l}\text { with four } \\
\text { stiffeners } \\
\text { (FS) at } \\
\text { both ends }\end{array}$ & Q235 & $\begin{array}{c}1 \text { st cycle at } \\
1 / 75 L\end{array}$ & 3.08 & 3.23 & -- & 0.49 & 0.51 & -- \\
\hline & $\begin{array}{l}\text { OT550-25- } \\
\text { IT480-14- } \\
\text { GP10-L15-CT }\end{array}$ & \multirow{3}{*}{$\begin{array}{l}\text { with } \\
\text { gradually } \\
\text { changed } \\
\text { thickness } \\
(\mathrm{CT}) \text { at } \\
\text { both ends }\end{array}$} & Q235 & $\begin{array}{c}1 \text { st cycle at } \\
1 / 75 \mathrm{~L}\end{array}$ & 3.11 & 3.22 & -- & 0.49 & 0.51 & -- \\
\hline & $\begin{array}{c}\text { OT550-25- } \\
\text { IT480-14- } \\
\text { GP10-L15-CT }\end{array}$ & & $\begin{array}{c}\text { LYP22 } \\
5[33]\end{array}$ & $\begin{array}{c}2 \text { nd cycle at } \\
1 / 75 L\end{array}$ & 3.25 & 3.42 & 3.42 & 0.52 & 0.54 & 0.54 \\
\hline & $\begin{array}{l}\text { OT550-25- } \\
\text { IT480-14- } \\
\text { GP10-L15-CT }\end{array}$ & & $\begin{array}{c}\text { EN } \\
1.4301 \\
{[34]}\end{array}$ & $\begin{array}{c}2 \text { nd cycle at } \\
1 / 75 L\end{array}$ & 2.47 & 2.89 & 3.03 & 0.39 & 0.46 & 0.48 \\
\hline
\end{tabular}


Table 6. Dimensions for the parametric FE models with different gap sizes

\begin{tabular}{|c|c|c|c|c|c|c|}
\hline \multirow[b]{2}{*}{ Specimens } & \multirow[b]{2}{*}{ Remarks } & \multirow{2}{*}{$\begin{array}{c}\text { Gap size } \\
\text { (mm) }\end{array}$} & \multicolumn{2}{|c|}{ Outer tube } & \multicolumn{2}{|c|}{ Inner tube } \\
\hline & & & $\begin{array}{l}\text { Diameter } \\
(\mathrm{mm})\end{array}$ & $\begin{array}{l}\text { Thickness } \\
(\mathrm{mm})\end{array}$ & $\begin{array}{l}\text { Diameter } \\
(\mathrm{mm})\end{array}$ & $\begin{array}{c}\text { Thickness } \\
\text { (mm) }\end{array}$ \\
\hline $\begin{array}{l}\text { OT542.6-26.3- } \\
\text { IT480-14-GP5- } \\
\text { L15-ES }\end{array}$ & \multirow{3}{*}{$\begin{array}{l}\text { with eight } \\
\text { stiffeners } \\
\text { (SS) at } \\
\text { both ends }\end{array}$} & 5 & 542.6 & 26.3 & 480.0 & 14.0 \\
\hline $\begin{array}{c}\text { OT550-25- } \\
\text { IT480-14- } \\
\text { GP10-L15-ES }\end{array}$ & & 10 & 550.0 & 25.0 & 480.0 & 14.0 \\
\hline $\begin{array}{c}\text { OT565.4-22.7- } \\
\text { IT480-14- } \\
\text { GP15-L15-ES }\end{array}$ & & 20 & 565.4 & 22.7 & 480.0 & 14.0 \\
\hline $\begin{array}{l}\text { OT542.6-26.3- } \\
\text { IT480-14-GP5- } \\
\text { L15-CT }\end{array}$ & \multirow{3}{*}{$\begin{array}{l}\text { with } \\
\text { gradually } \\
\text { changed } \\
\text { thickness } \\
(\mathrm{CT}) \text { at } \\
\text { both ends }\end{array}$} & 5 & 542.6 & 26.3 & 480.0 & 14.0 \\
\hline $\begin{array}{c}\text { OT550-25- } \\
\text { IT480-14- } \\
\text { GP10-L15-CT }\end{array}$ & & 10 & 550.0 & 25.0 & 480.0 & 14.0 \\
\hline $\begin{array}{l}\text { OT565.4-22.7- } \\
\text { IT480-14- } \\
\text { GP15-L15-CT }\end{array}$ & & 20 & 565.4 & 22.7 & 480.0 & 14.0 \\
\hline
\end{tabular}




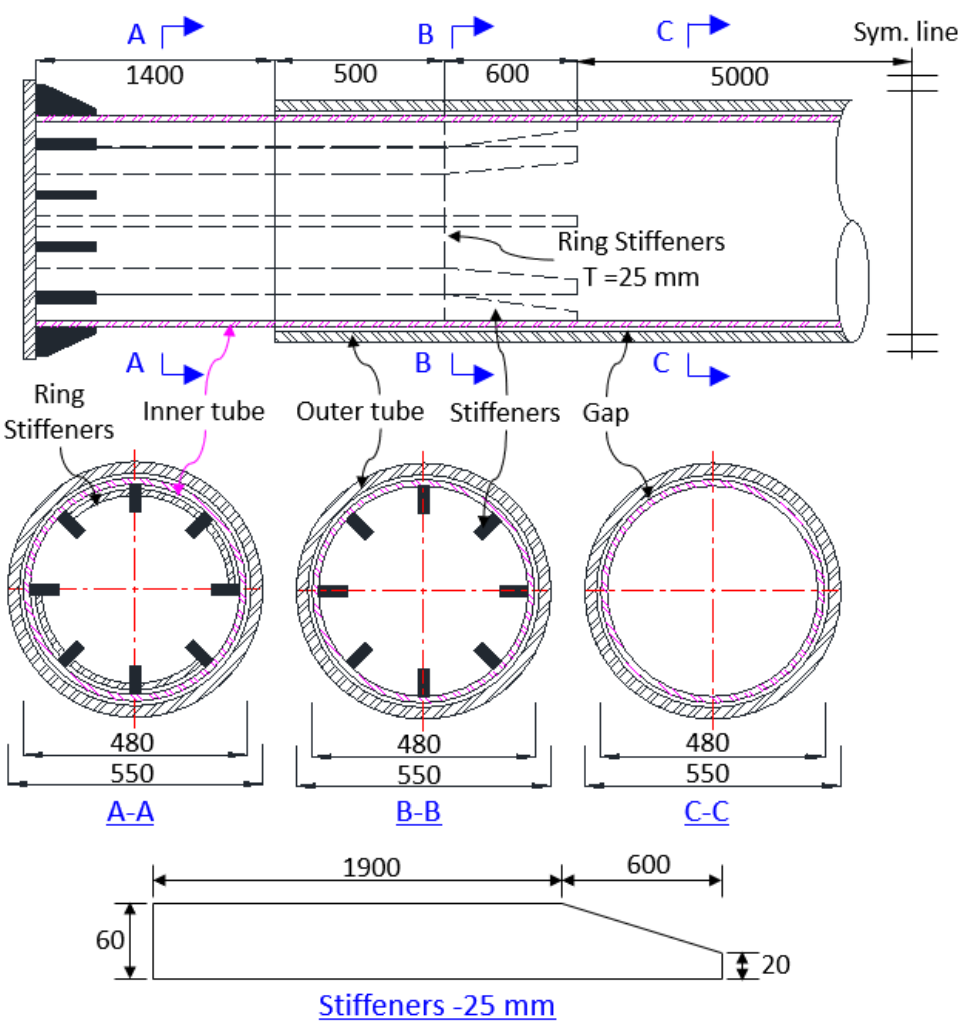

(a) Schematic view

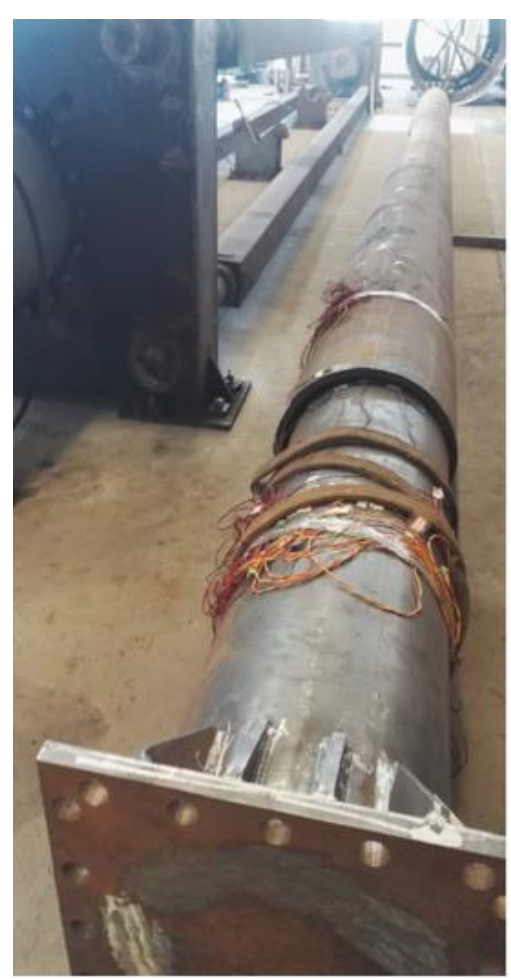

Test specimen
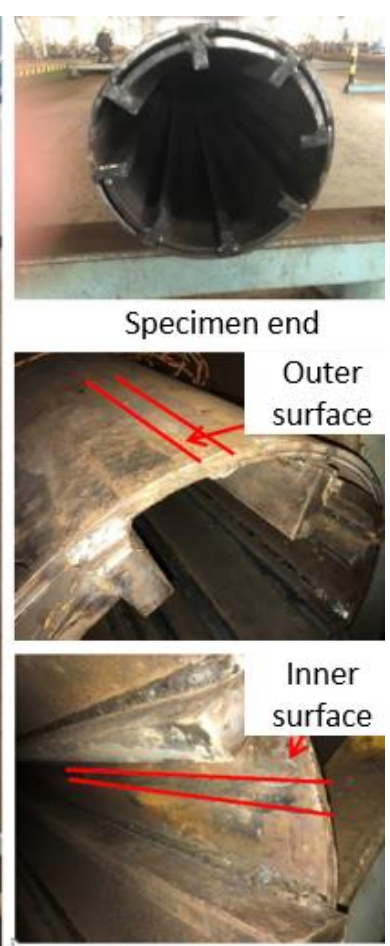

Straight seam weld of Inner tube

(b) Photos

Figure 1. Test specimen 


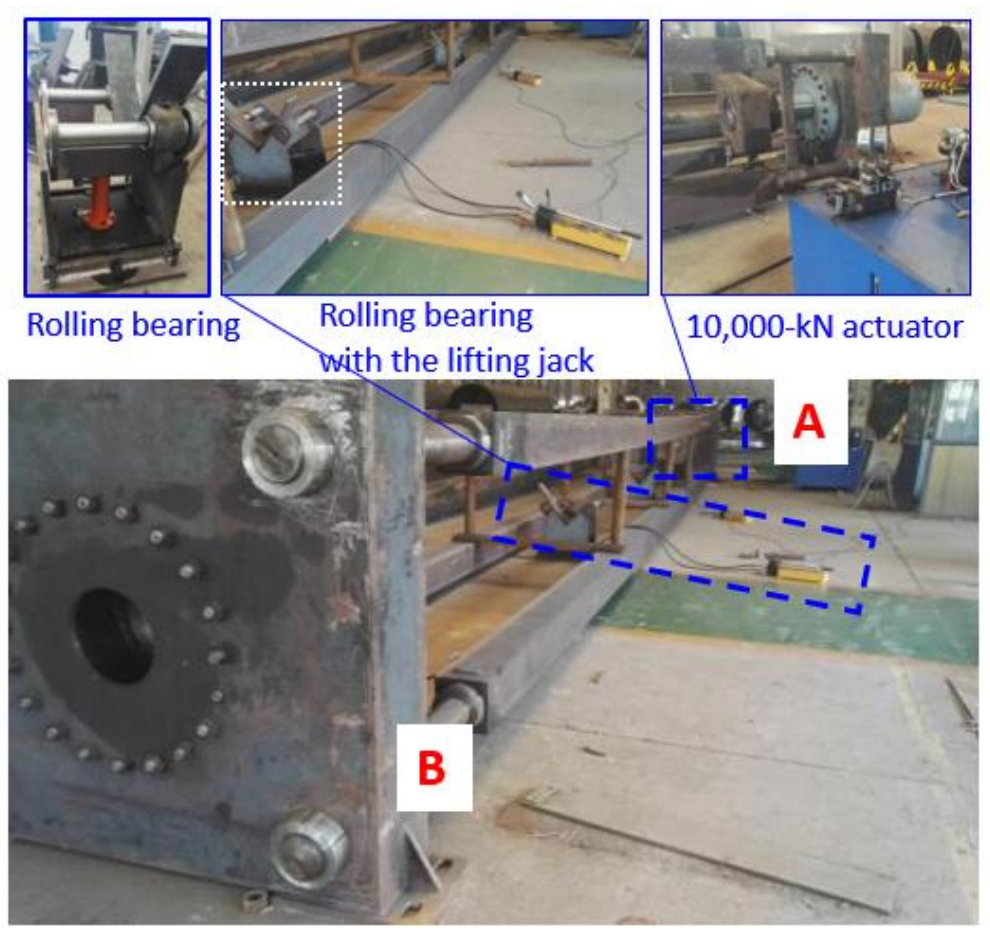

(a) Set-up

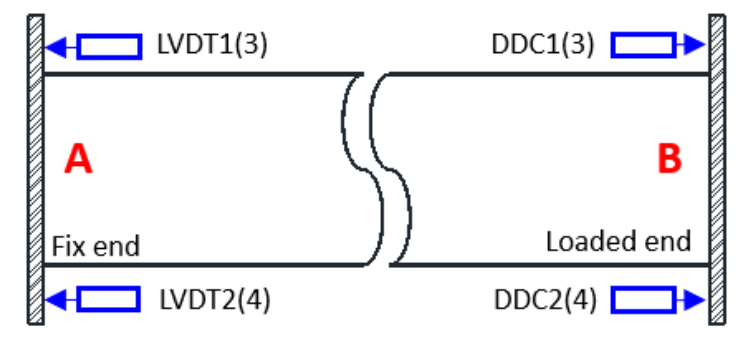

(b) Displacement memurement

Figure 2. Test setup 


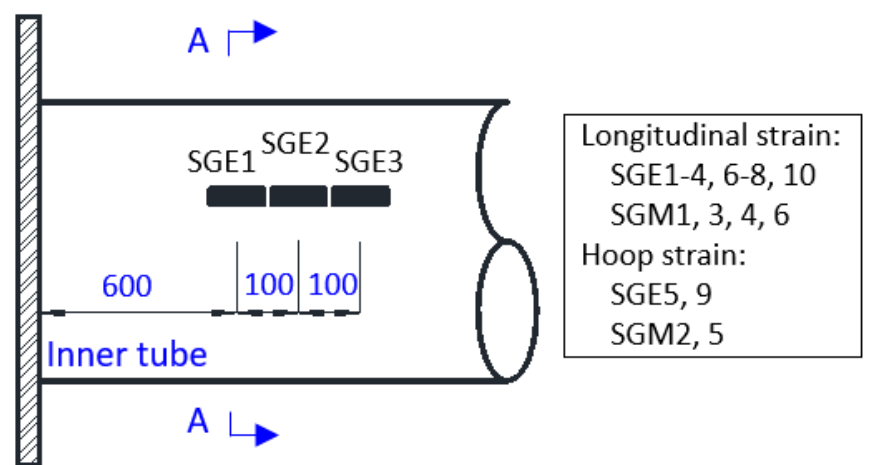

(a) Tube end

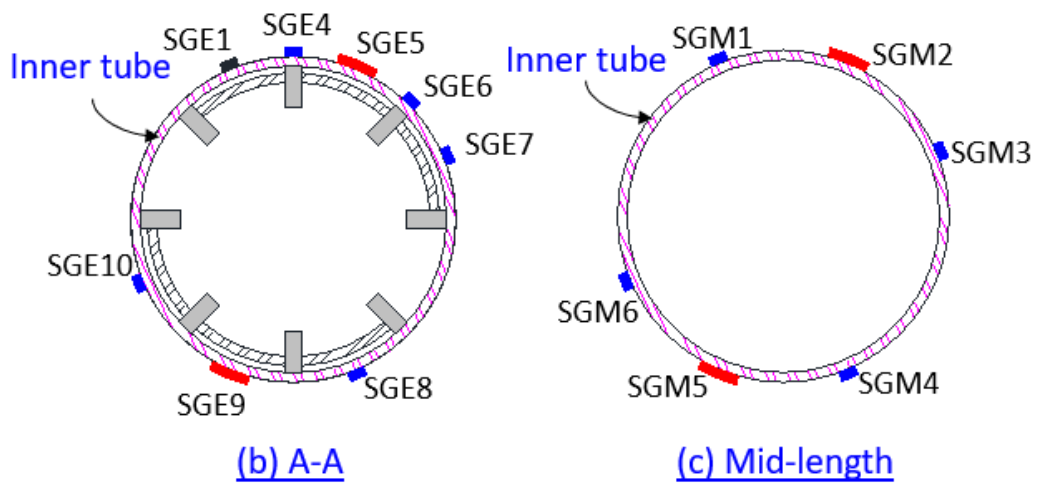

Figure 3. Location of the strain gauges 


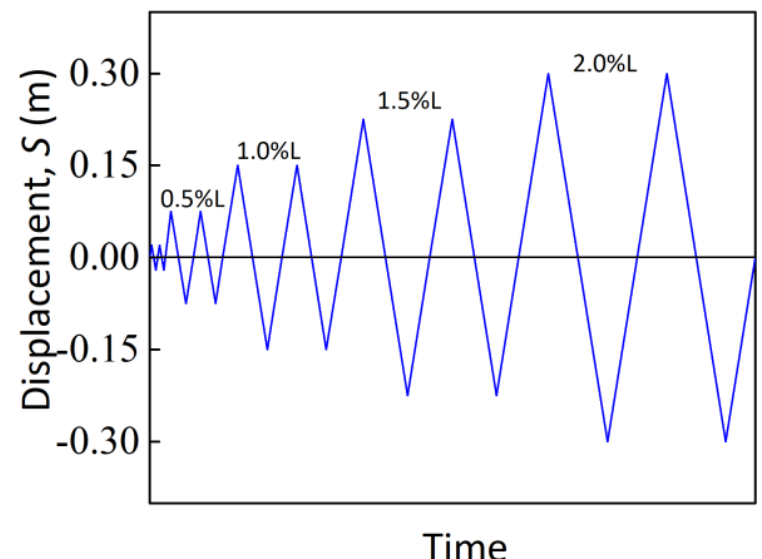

Figure 4. Loading protocol 


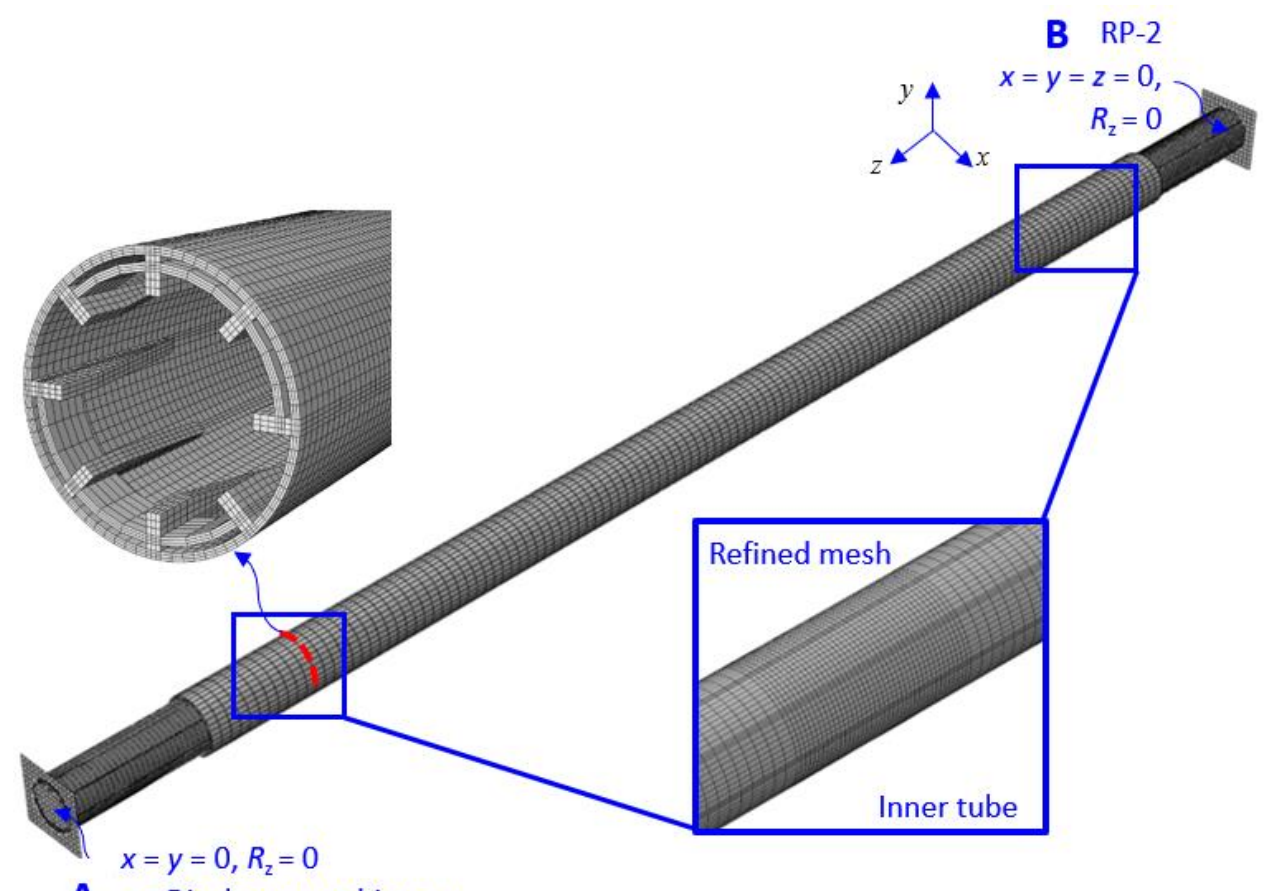

A $z=$ Displacement history

Figure 5. Finite element model 


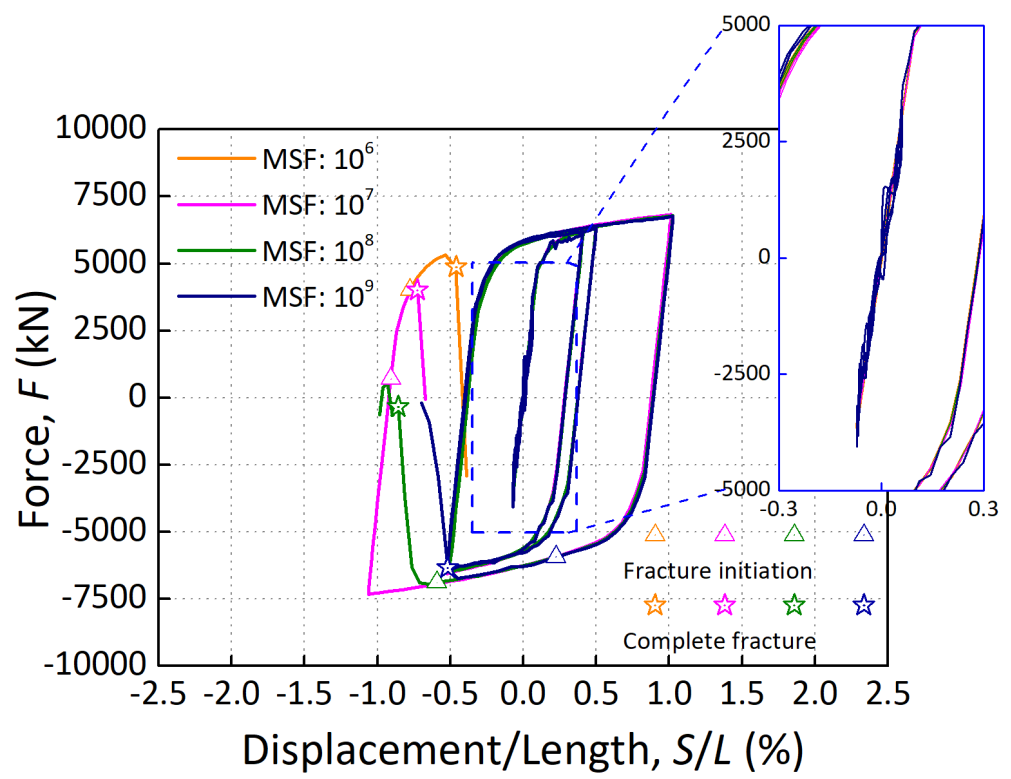

(a) Effect of MSFs

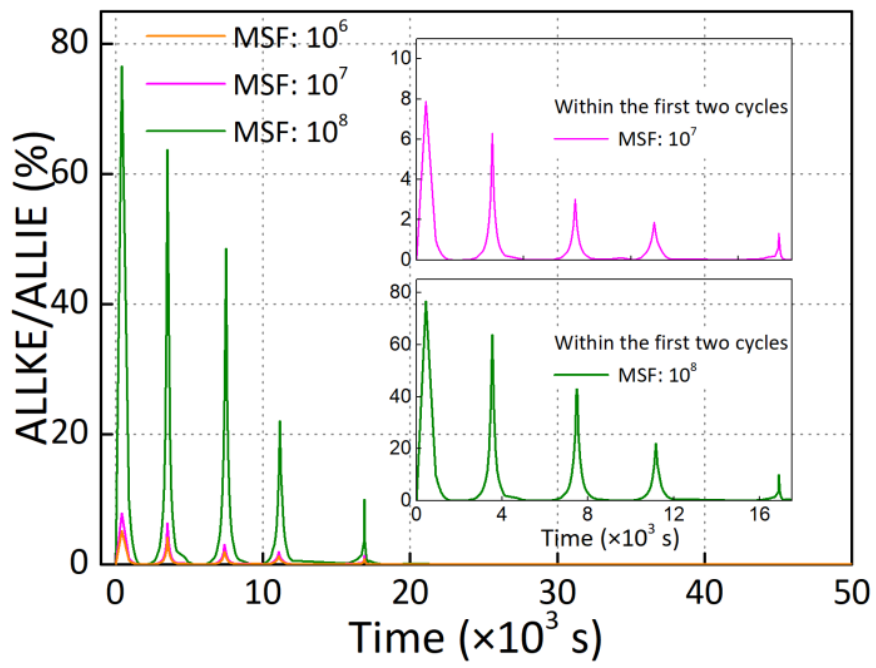

(b) ALLKE/ALLIE

Figure 6. Comparison of hysteretic responses from test and simulation 


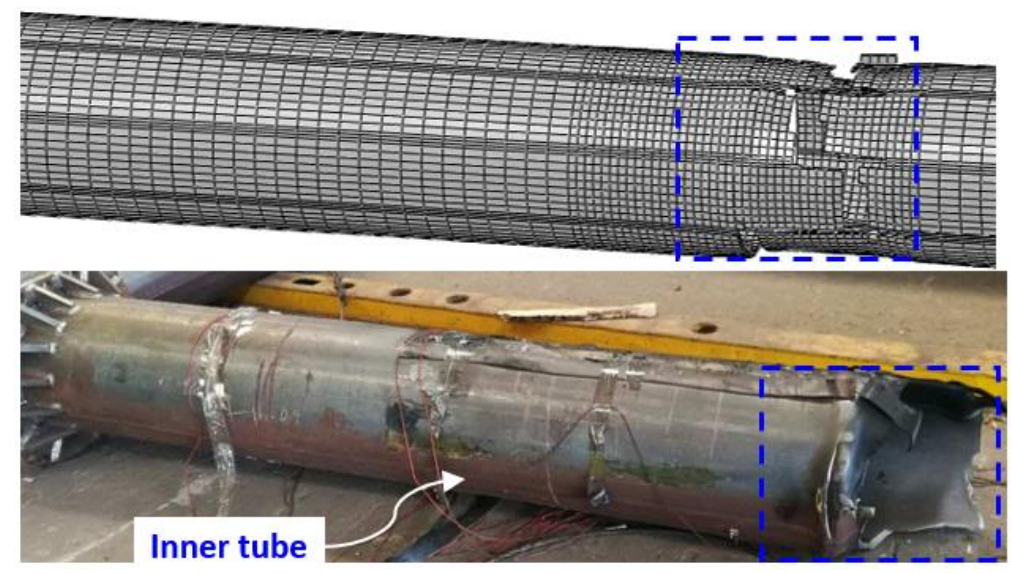

(a) Global view

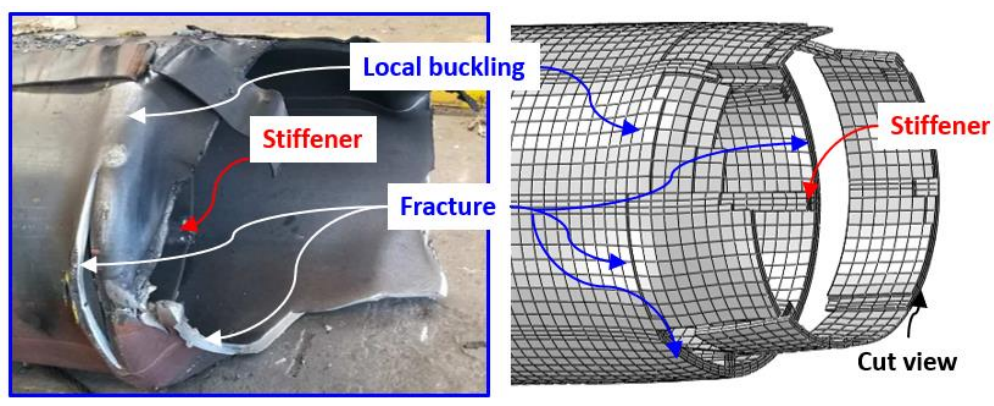

(b) Local view

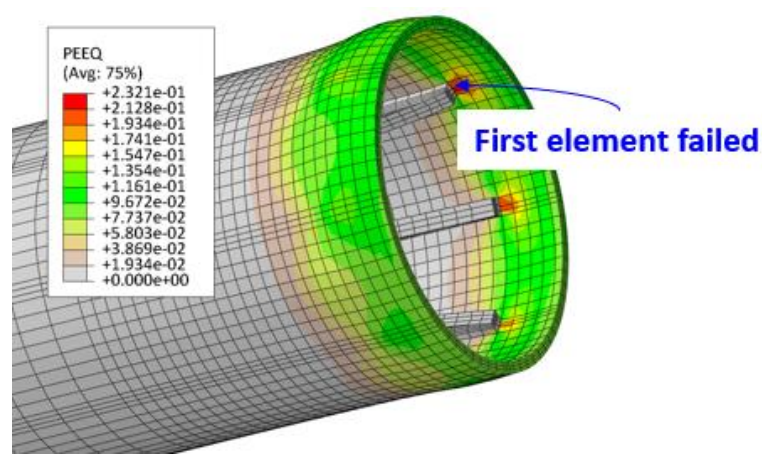

(c) Equivalent plastic strain at fracture initiation

Figure 7. Failure mode of the test specimen and FE model (Eight times magnified deformations at the cross-section) 


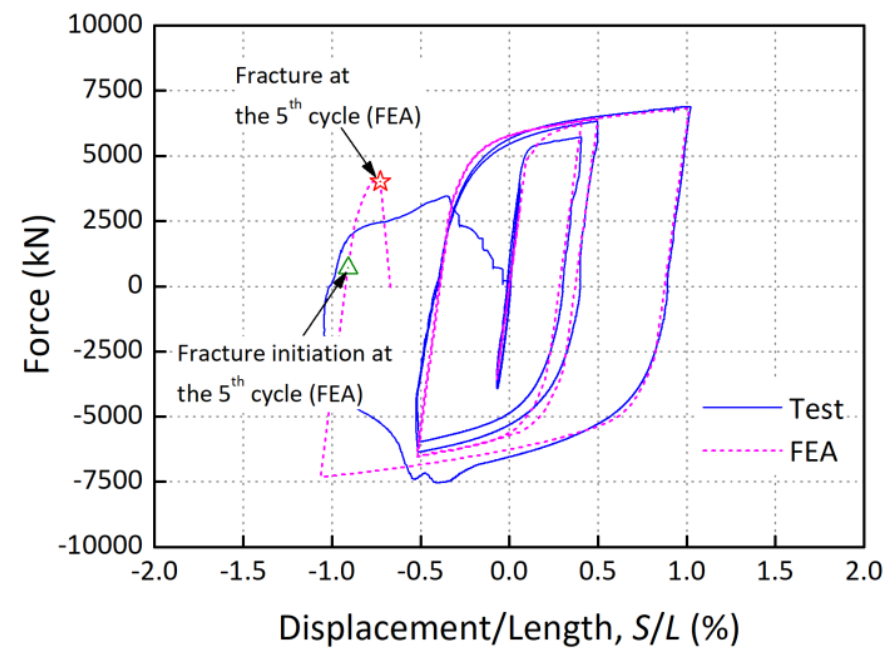

Figure 8. Comparison of hysteretic responses from test and simulation 


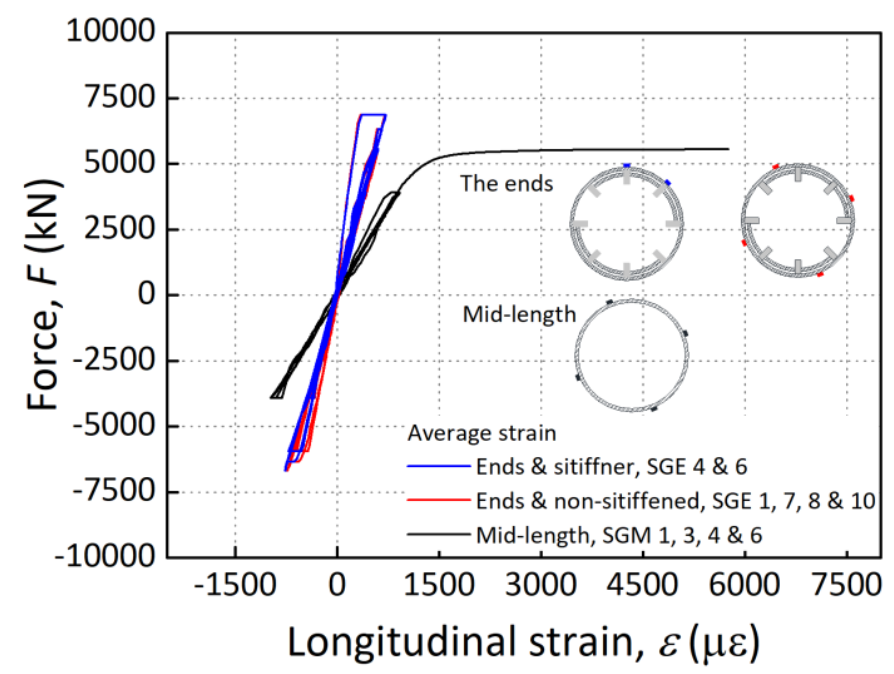

(a)

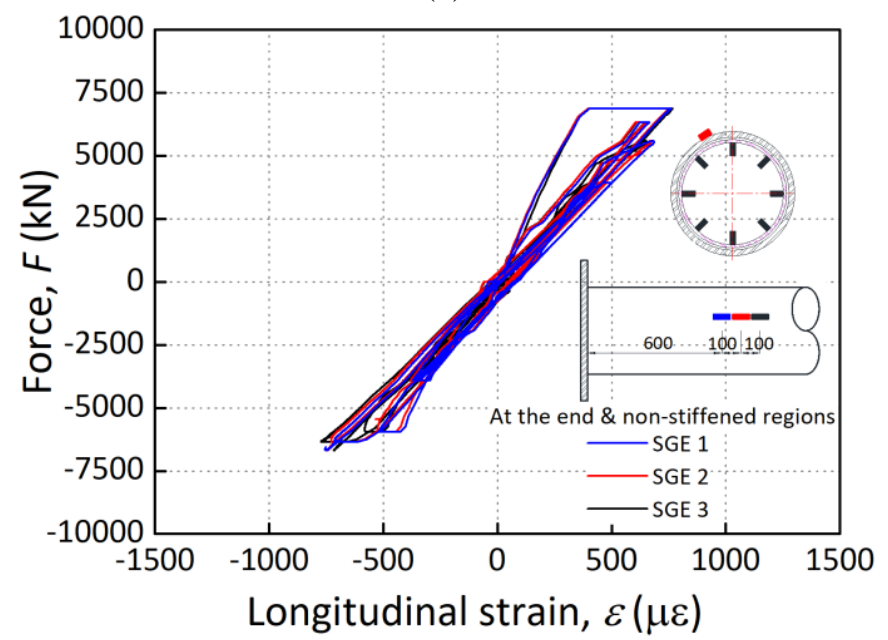

(b)

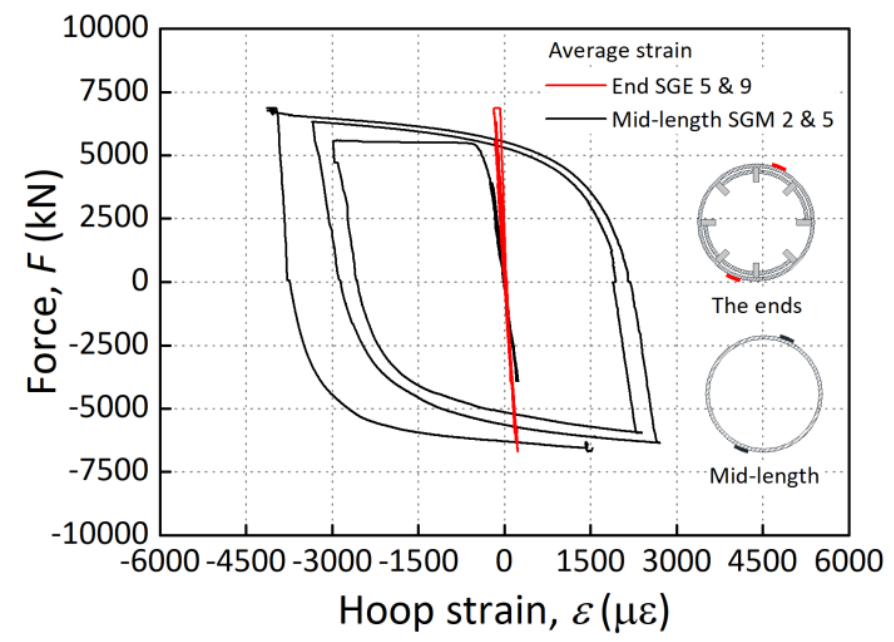

(c)

Figure 9. Average values of measured strains 


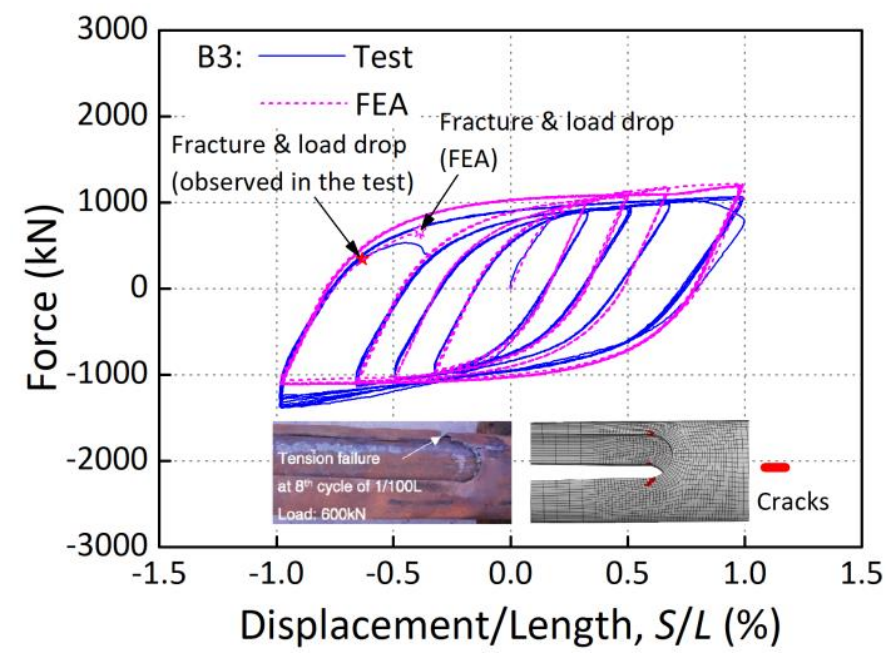

(a) B3

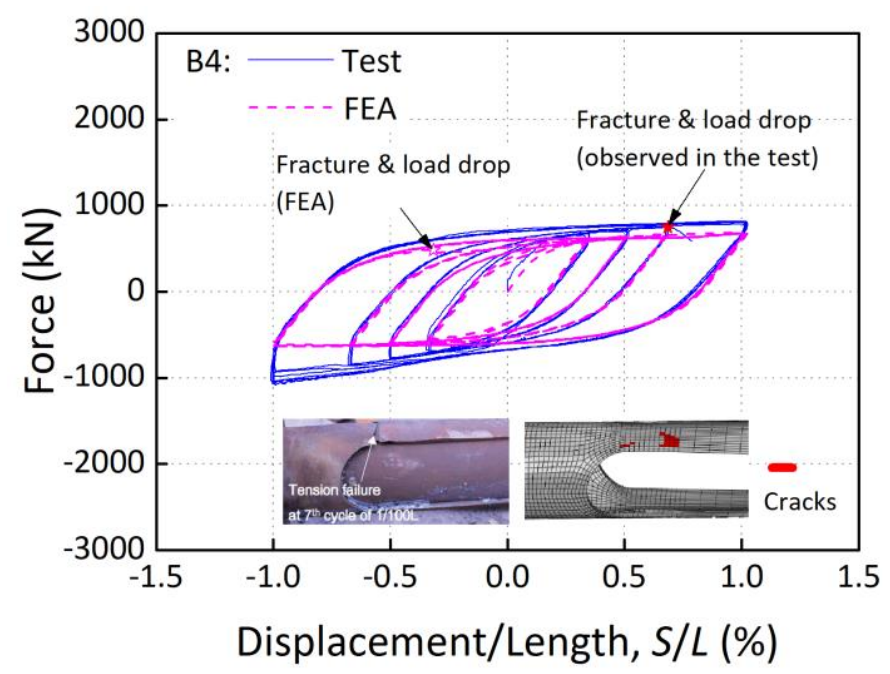

(b) B4

Figure 10. Comparison of hysteretic responses from test and simulation [9] 


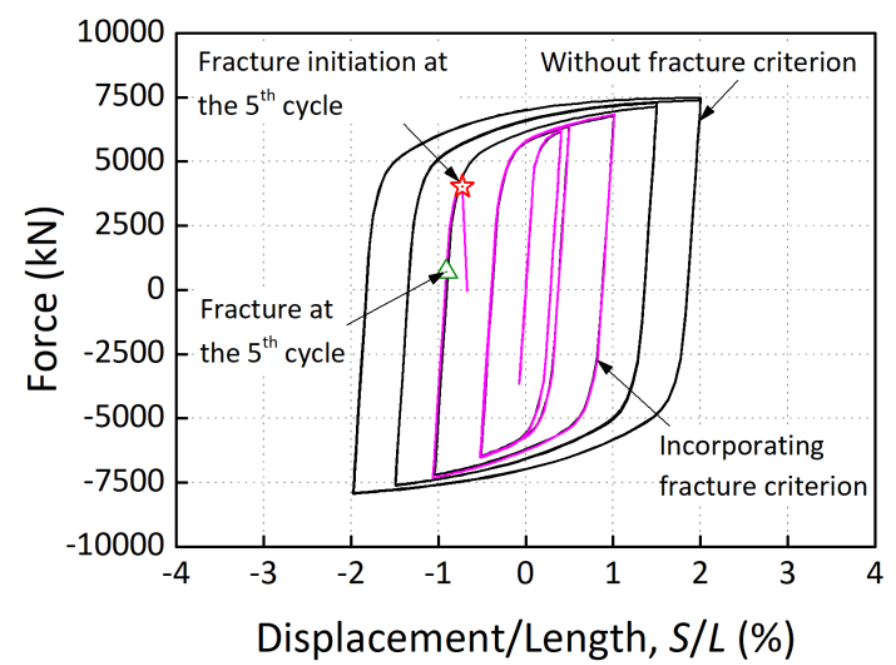

(a) Test specimen

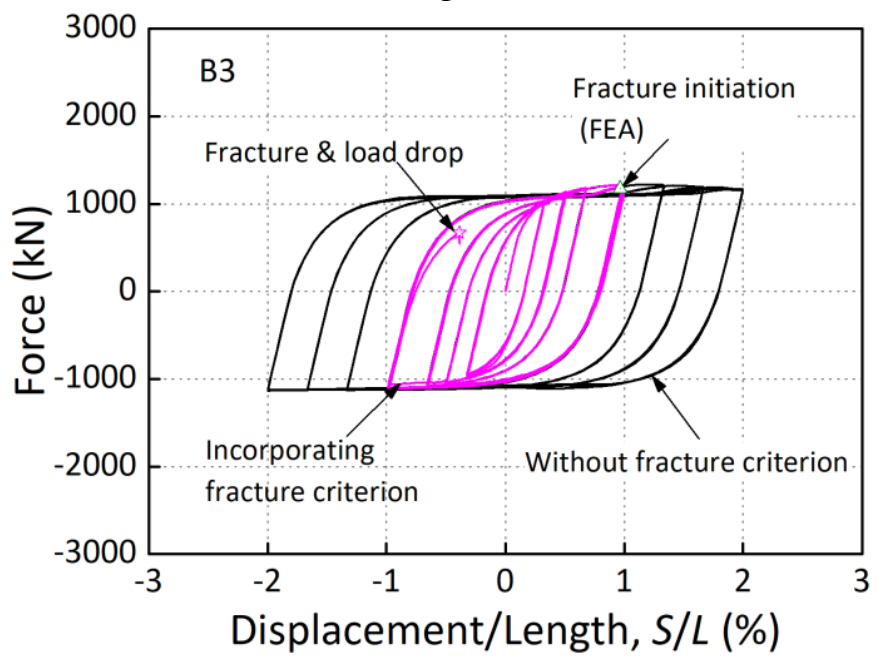

(b) B3 [9]

Figure 11. Comparison of hysteretic responses from different FE models 


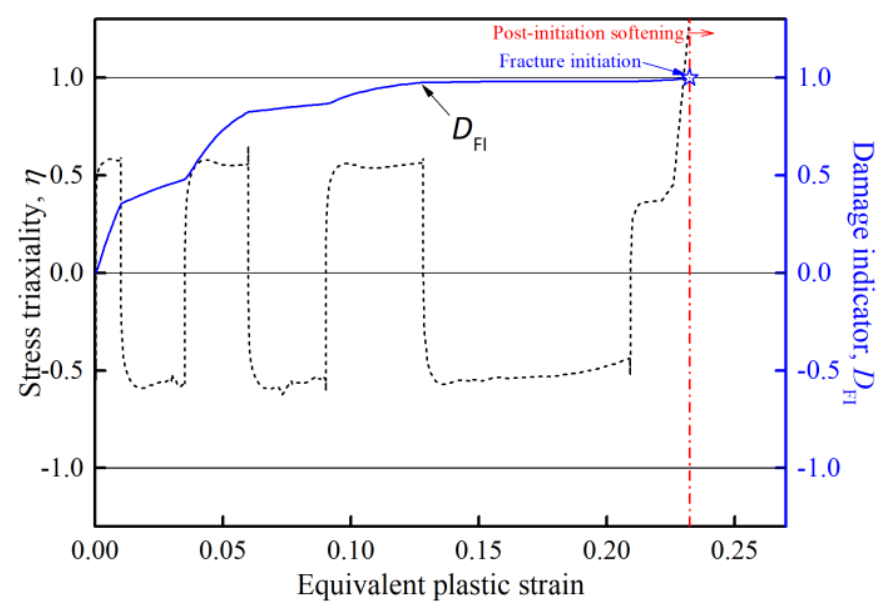

(a) Stress triaxiality

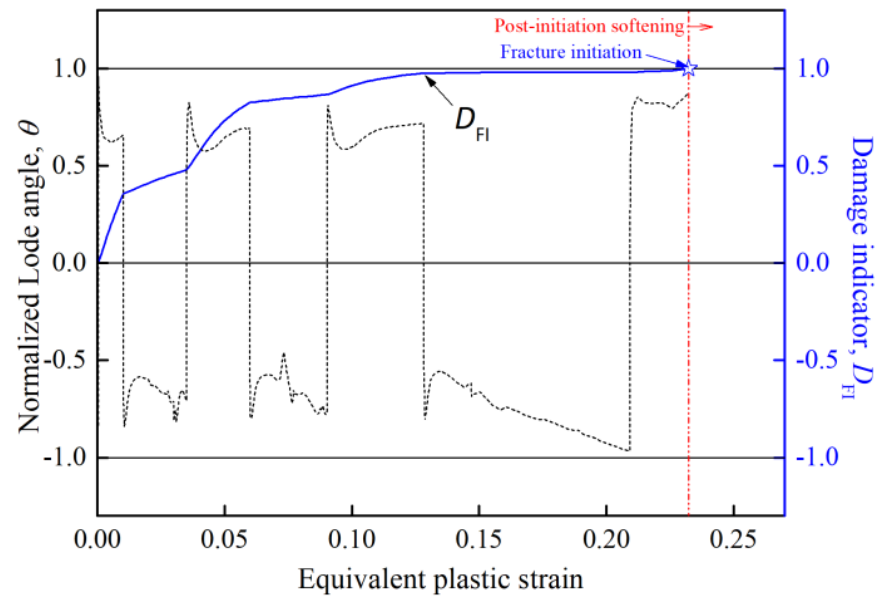

(b) Normalized Lode angle

Figure 12. Relationship of fracture index with (a) stress triaxiality (b) normalized Lode angle 


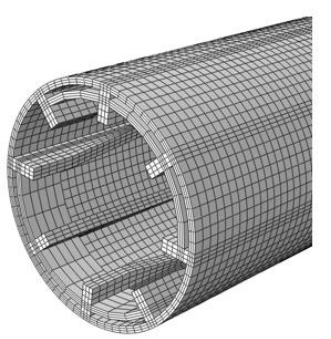

Eight-stiffener

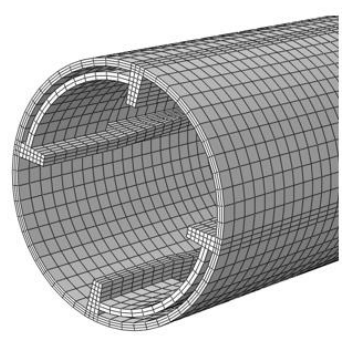

Four-stiffener

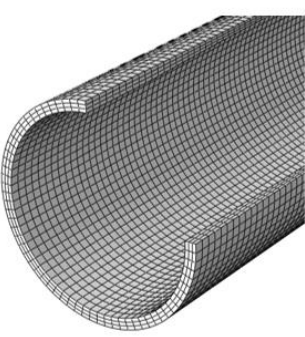

Changeable-thickness

(a) Schematic view of different end sections

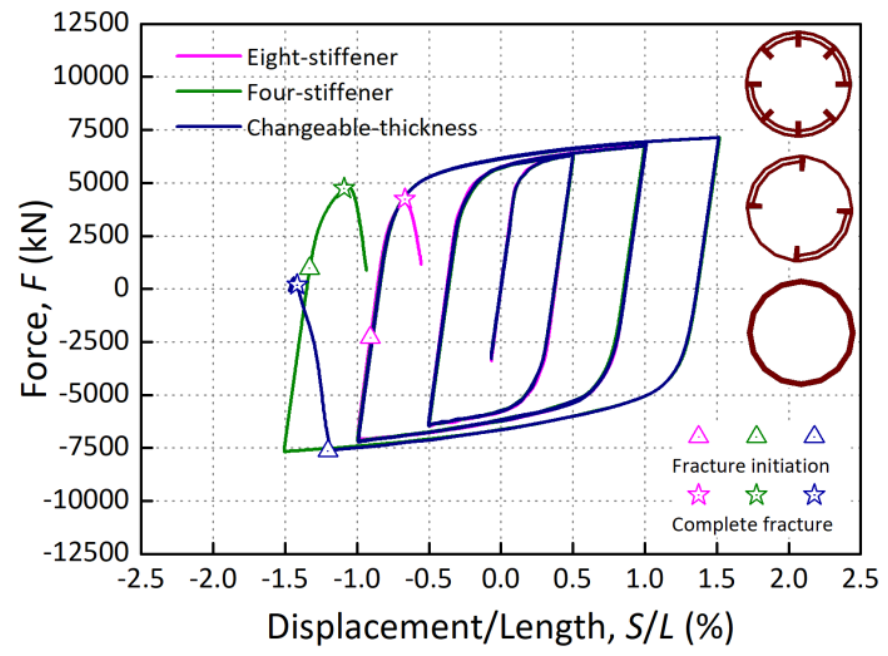

(b) Hysteretic curves

Figure 13. Effects of the stiffener arrangements 


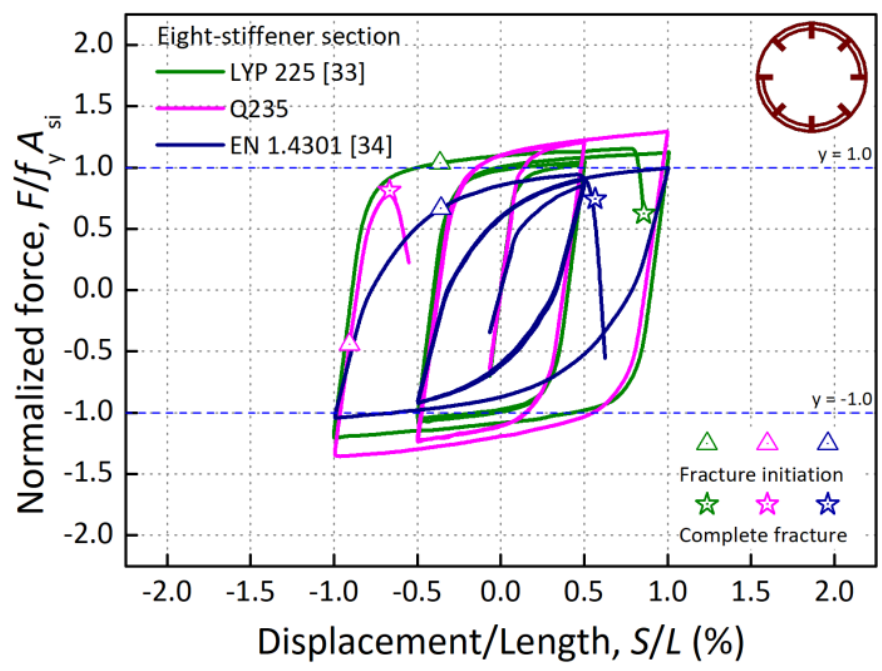

(a) Eight-stiffener section

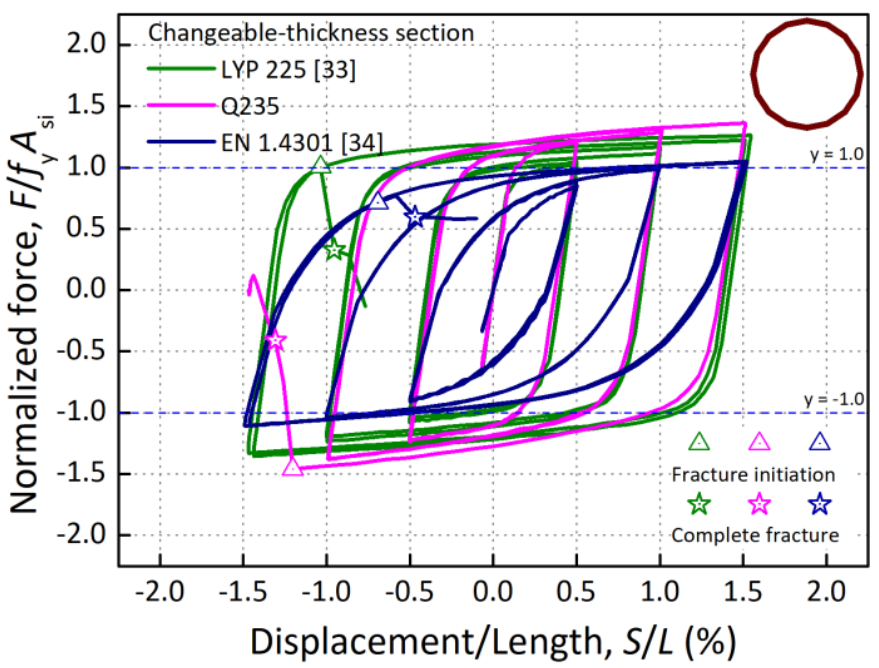

(b) Changeable-thickness section

Figure 14. Effects of material properties 


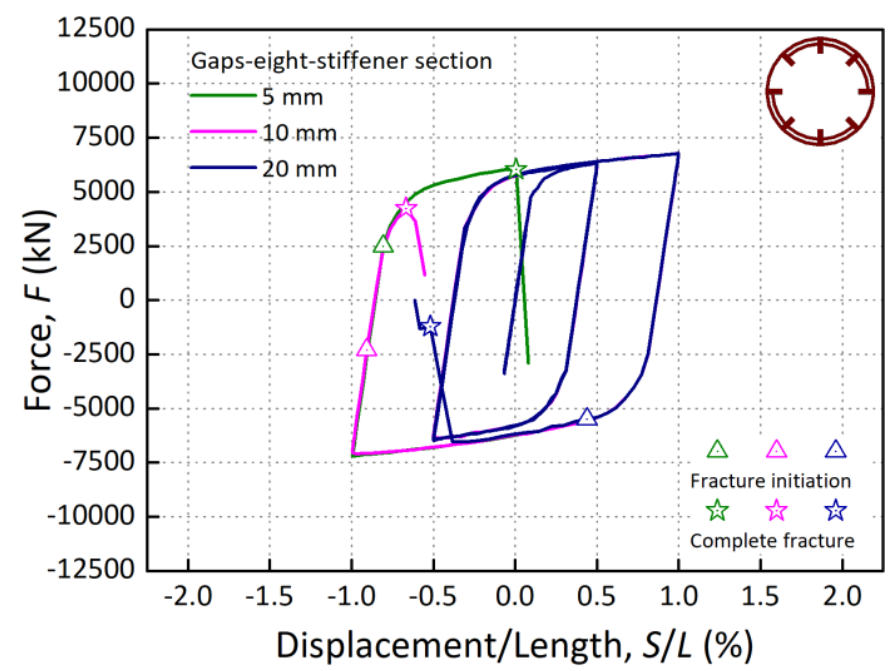

(a) Eight-stiffener section

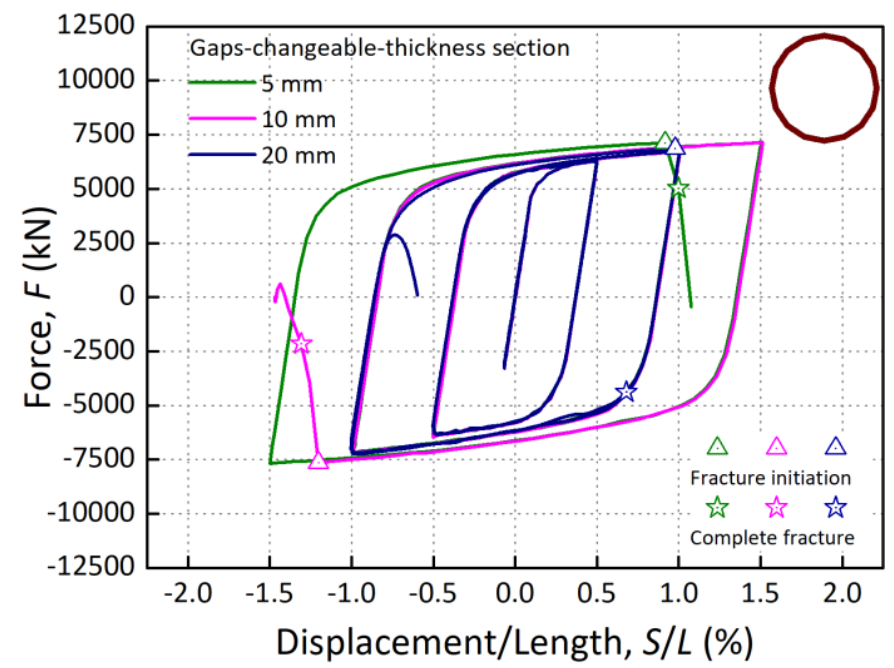

(b) Changeable thickness section

Figure 15. Effects of gap size 


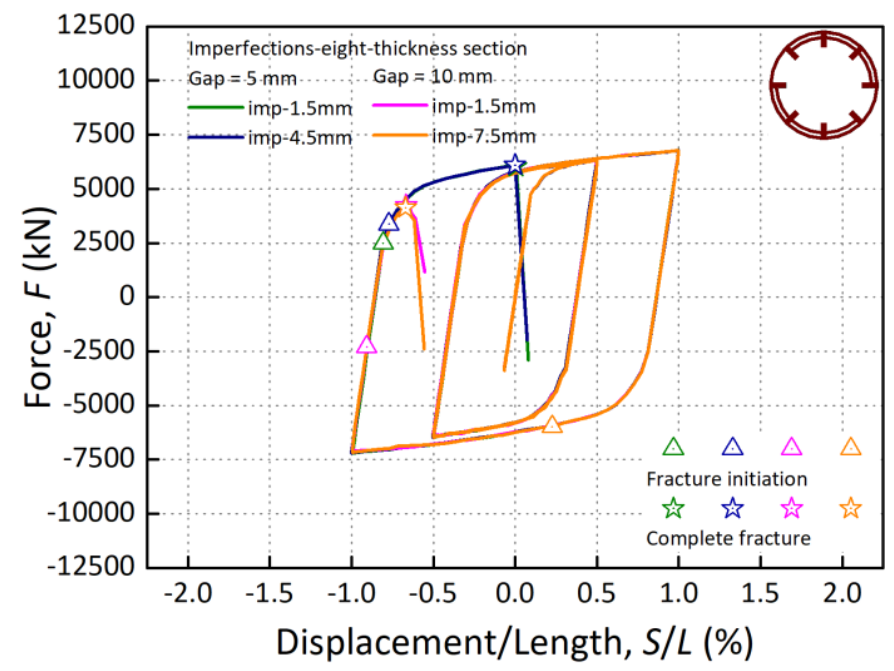

(a) Eight-stiffener section

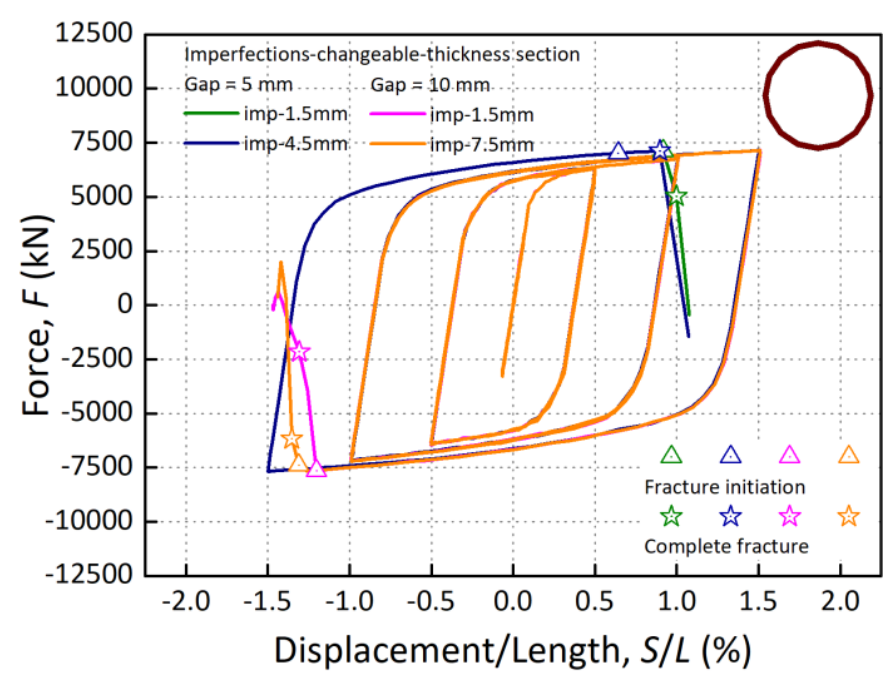

(b) Changeable thickness section

Figure 16. Effects of global imperfections 


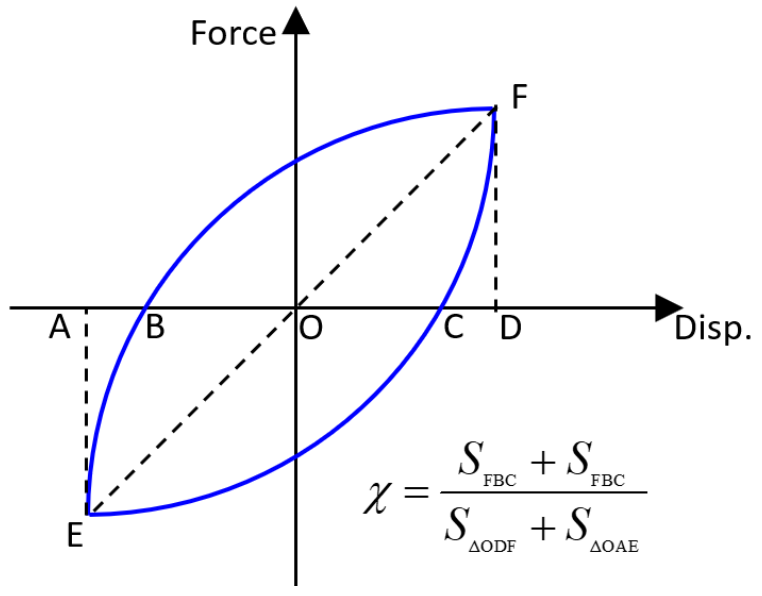

Figure 17. Schematic view for the definition of $\chi$ 